\title{
DE LA CAUSALIDAD ADECUADA A LA IMPUTACIÓN OBJETIVA EN LA RESPONSABILIDAD CIVIL COLOMBIANA*
}

\section{FROM ADEGUATE CAUSATION TO PROXIMATE CAUSATION IN COLOMBIA'S CIVIL LIABILITY}

\author{
Sergio Rojas-Quiñones** \\ Juan Diego Mojica-Restrepo*** \\ Fecha de recepción: 2 de marzo de 2014 \\ Fecha de aceptación: 08 de mayo de 2014 \\ Disponible en linea: 30 de julio de 2014
}

\section{Para citar este articulo/To cite this article}

\author{
Rojas-Quiñones, Sergio \& Mojica-Restrepo, Juan Diego, De la causalidad \\ adecuada a la imputación objetiva en la responsabilidad civil colombiana, \\ 129 Vniversitas, 187-235 (2014). http://dx.doi.org/10.11144/Javeriana.VJ129. \\ caio
}

doi:10.11144/Javeriana.VJ129.caio

\footnotetext{
* Este artículo es resultado preliminar de una investigación que tiene curso en el grupo de investigación en Derecho Privado de la Facultad de Ciencias Jurídicas de la Pontificia Universidad Javeriana de Bogotá.

** Abogado de la Facultad de Ciencias Jurídicas, Pontificia Universidad Javeriana de Bogotá. Actualmente, candidato a máster en la maestría oficial en Derecho de Daños, Universidad de Girona, España. Así mismo, es miembro del Centro de Estudios de Derecho Privado de la Pontificia Universidad Javeriana, investigador del grupo de investigación en Derecho Privado y profesor titular de la cátedra de responsabilidad civil I de la misma Universidad. Es asociado de la firma Salazar, Pardo \& Jaramillo Abogados, Bogotá, Colombia. Ha escrito varios textos académicos relacionados con la responsabilidad civil y el derecho de obligaciones. Correo electrónico: srojas@spjlaw.com

*** Graduando de la Facultad de Ciencias Jurídicas, Pontificia Universidad Javeriana de Bogotá. Director de la revista Universitas Estudiantes. Miembro del semillero de investigación en Derecho Procesal de la Universidad Javeriana. También es miembro del grupo de investigación en Derecho Civil de la misma universidad en las líneas de investigación en Responsabilidad Civil y Contratos. Actualmente, vinculado a Gómez y Solarte Abogados, Bogotá, Colombia. Correo electrónico: jdmojica@gomezalzate.com
} 


\section{RESUMEN}

Tradicionalmente, la atribución de un resultado dañoso a su autor se ha hecho a partir de un juicio puramente material o fáctico, en el cual, dependiendo de la teoría causal utilizada por el tribunal, la respuesta sobre la existencia de un nexo de causalidad entre el perjuicio irrogado y la actuación del agente puede variar, a la vez que arrojar resultados que, a la luz de la equidad y la justicia, e incluso el sentido común, llegan a resultar exagerados o contraintuitivos. El presente documento aborda esta problemática para presentar, previo recuento de las diferentes soluciones que se le han dado a lo largo de la historia y de sus inconvenientes, la que se considera la teoría más adecuada para determinar la causalidad en cada caso, por superar los defectos que se les achacan a aquellas que la precedieron y por su aceptación en el ámbito comparado. Con esta propuesta, se intenta evidenciar cómo, a partir de la diferenciación entre una imputación material y una imputación jurídica (o imputación objetiva), se logran resultados más acordes a la noción de justicia que subyace a la responsabilidad civil. Con todo, no se desconocen las críticas que se le pueden hacer a esta teoría, por lo que se presentan las alternativas que se consideran más idóneas para dar respuesta a estos señalamientos.

Palabras claves: responsabilidad civil; causalidad; causalidad de hecho; causalidad de derecho; causa adecuada; imputación objetiva. 


\section{ABSTRACT}

Traditionally, the assignment of a harmful result to its author has been done from a purely material or factual judgment in which, depending on the causal theory used by the court, the answer to the existence of a causal link between the damage suffered and the action of the agent may vary, as well as yield results that, in light of equity and justice, and even common sense, come to be exaggerated or counterintuitive. This paper addresses this problem, once described the different solutions that have been given throughout history and its drawbacks, it presents what is considered the most appropriate theory to determine causality in each case, to overcome the defects that were blamed on those that preceded them and its acceptance in the comparative field. It reveals how, from the differentiation between imputation and proximate causation, results are more consistent with the concept of justice underlying civic liability. However, criticisms towards this theory were not unknown; therefore alternatives considered to be more suitable to answer these remarks are presented.

Key words: Civil liability; causation; adequate cause; proximate Causation.

\section{SUMARIO}

INTRODUCCIÓN.- I. CAUSALIDAD EN MATERIA DE RESPONSABILIDAD CIVIL. UNA APROXIMACIÓN A LAS DIFERENTES TEORÍAS.- II. LA TESIS DE LA CAUSALIDAD

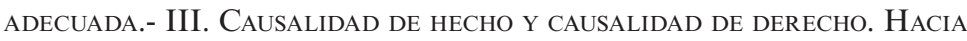
UNA TEORÍA DE LA IMPUTACIÓN OBJETIVA.- CONCLUSIÓN.- BibLIOGRAFÍA. 
La causalité n'est pas quelque chose que se voit et se touche, mais un rapport

déduit des circonstances de fait par une opération de l'esprit.

René Savatier, 1951

\section{INTRODUCCIÓN}

El nexo de causalidad, entendido como la "necesaria conexión fáctica que debe existir entre la acción humana y el resultado dañoso producido", es uno de los presupuestos fundamentales para la prosperidad de cualquier pretensión indemnizatoria en el marco de la responsabilidad civil. No en vano, se trata de uno de aquellos elementos que resultan imprescindibles en cualquier tradición jurídica, ya sea en el derecho de daños continental (civil law) o en el anglosajón (common law) ${ }^{2}$.

Colombia no es la excepción a este aserto. El artículo 2341 del Código Civil indica: "el que ha cometido un delito o culpa, que ha inferido daño a otro, es obligado a la indemnización (...)"3, de donde se colige que solo a quien le resulte imputable la conducta, a título de acción u omisión, le es atribuible la responsabilidad. Así, quienes no son los detonantes causales del resultado no pueden, en modo alguno, ser obligados a indemnizar o, puesto en otros

1 Ramón Daniel Pizarro, Responsabilidad civil por riesgo creado y de empresa. Contractual y extracontractual, tomo I, 87, Editorial La Ley, Buenos Aires (2006).

2 Sobre la similitud en la concepción de la causalidad en el Common Law y el Civil Law, Eric Engle expone: "Causation is one of the most complex and unclear aspects of tort law. However, common law and civil law reach surprisingly similar legal solutions about the problem of causation despite the fact that the problem of causation in tort law is, at least in theory, factually indeterminate. Legal convergence in tort law was not merely a pragmatic result of economic facts. It was also implicit in common philosophical presuppositions about causality in national law which influenced tort law in both common law and civil law countries and provided the basic superstructural framework for legal convergence". ERIC ENGLE, Aristotelian Theory and Causation: The Globalization of Tort, 2 Gujarat National Law University Law Review, 1, 1-18, 3 (octubre de 2009). Disponible en: http://papers.ssrn.com/sol3/papers. cfm?abstract_id=1424693. Sobre la causalidad en el Common Law, el profesor estadounidense Larry Alexander afirma: "[t]he fact that a particular defendant's conduct was a 'but for' cause of an injury to a particular plaintiff, which fact is a necessary condition for the plaintiffs recovering corrective damages from the defendant, is the fundamental building block of all tort law. Regardless of what other conditions, if any, tort law imposes as necessary for plaintiff's recovering from the defendant — proximate causation, foreseeability, negligence or recklessness or intent, design defect — a 'but for' causal link between the plaintiff's injury and the defendant's conduct is essential. No causation, no tort”. Larry A. Alexander, Causation and Corrective Justice: Does Tort Law Make Sense?, 6 Law and Philosophy, 1, 1-23, 1 (April, 1987).

3 Código Civil, Ley 57 de 1887. Disponible en: http://www.alcaldiabogota.gov.co/sisjur/normas/ Norma1.jsp?i $=39535$ 
términos, solo quien ha dado lugar al daño - lo ha causado — tiene legitimación pasiva para ser condenado.

Lo anterior no es sino lógica consecuencia de la estructura misma de la responsabilidad y, más allá de eso, de la filosofía moral que subyace a ella. Ciertamente, la consecuencia natural de la libertad que se le reconoce a todo individuo por el solo hecho de ser persona, supone, entre otras, que ese individuo se apropie de sus acciones y de los resultados a que estas conducen. En ese orden de ideas, solo podemos reconocer la idea de libertad si entendemos que, como agentes, somos el dominus de lo que hacemos o dejamos de hacer y, de contera, somos responsables por sus resultados. Este es el presupuesto de la teoría de la agencia que, se itera, nos reconoce como libres pero, a su turno, como responsables. Naturalmente, esta idea tiene una contracara que también debe ser clara: así como somos dueños - y, por ello, responsables - de nuestras acciones, no lo somos de las acciones de otros; lo que haga o deje de hacer un tercero no compromete nuestra responsabilidad por la sencilla razón de que no somos dueños de tales acciones; ese es el presupuesto fundamental de la libertad.

Pues bien, todo ello se hace patente en la exigencia del vínculo de causalidad. La mejor expresión de que solo somos responsables por los resultados que causemos es la causalidad que, en ese orden de ideas, se erige como la versión jurídica del principio moral de la agencia, en virtud del cual, como somos dueños de nuestras propias acciones, somos también dueños de sus resultados. Allí estriba la importancia de la causalidad. Con todo, si bien resulta indiscutible que solo quien con su actuar ha causado un daño deberá repararlo, está claridad se pierde en una nube de complejidad e indeterminación al momento de establecer, en concreto, el vínculo causal entre el perjuicio irrogado y el actuar de quien es sindicado como agente dañador.

Al respecto, Obdulio Velásquez señala: "el sentido común se niega a admitir que la existencia de un daño sea soportada por quien no ha influido en la realización del mismo. Entonces se necesita una relación causa-efecto entre el acto humano y el daño que se produce, es decir, la causación del daño por el agente dañino es necesaria para que se configure responsabilidad civil, además del daño y la culpa. En ocasiones, la identificación de la causa no 
ofrece especiales dificultades para el operador del derecho, pero en otras, especialmente si concurren muchos factores que podrían ser causa de ese resultado dañoso, el determinar a la luz del derecho cuál o cuáles factores deben recibir la categoría de causa ofrece serias dificultades conceptuales y prácticas"4.

Estas dificultades tienen su punto de partida por fuera del Derecho, en la medida en que se remiten al mundo de la física y de la filosofía. Así, tradicionalmente se ha identificado que la cuestión del nexo causal ofrece dificultades desde la perspectiva conceptual (¿qué es la relación causa-efecto?), metafísica (¿qué es lo que ocurre en el mundo cuando aludimos a una conexión causal?) y epistemológica (¿cómo conocemos la causalidad?), lo que ha conducido a que, desde el empirismo, se acuñen las más diversas teorías para explicar este fenómeno, cada una situada en consideraciones diferentes y en el replanteamiento de los postulados de su predecesora: las teorías regularistas, las de los juicios contrafácticos, las probabilísticas y las teorías de los procesos fijos, por mencionar solamente los géneros más destacados.

En el Derecho, esta dificultad también se ha hecho patente, tanto en la esfera penal, como en la civil. En lo que concierne a esta última, el Derecho de daños ha debido enfrentarse a las conocidas problemáticas de la sobredeterminación causal, la incertidumbre en el nexo (causalidad alternativa con incertidumbre en el agente, causalidad alternativa con incertidumbre en la correspondencia agente-víctima, víctimas no identificadas e incremento de riesgo, por citar sus expresiones más representativas), la causa potencial, la causalidad alternativa hipotética, entre otras más. Como es obvio, las soluciones han sido disímiles y se han debatido entre los extremos de las reglas de preponderancia ('more probable than not' o reglas de 'todo o nada') y proporcionalidad o probabilidad, como se observa en los Principios de Derecho Europeo de la Responsabilidad Civil ${ }^{5}$.

4 Obdulio Velásquez-Posada, Responsabilidad civil extracontractual, 461, Editorial Temis, Bogotá (2009).

5 Grupo de derecho europeo de la responsabilidad civil, Principios de Derecho Europeo de la Responsabilidad Civil, PETL. Disponible en: http://civil.udg.edu/php/biblioteca/items/298/ PETLSpanish.pdf. En relación con las nuevas tendencias en materia de causalidad, debemos registrar el pronunciamiento del 16 de mayo de 2011, en el que la Sala de Casación Civil de la Corte Suprema de Justicia indicó: “...Admitida la variedad extremada de situaciones, a las concepciones de la prueba del nexo causal (causalidad eficiente, adecuada, equivalencia de condiciones, etc.) y mecanismos tradicionales de facilitación (prueba prima facie, Anscheinsbeweis 


\section{Esto ha llevado entonces a que la causalidad se erija como uno de los elementos de más difícil estudio al momento de adelantar un juicio de responsabilidad civil ${ }^{6}$.}

der Kausalität, res ipsa loquitur, id quod plerumque accidit, causalité virtuelle, inversión de la carga probatoria, presunciones hominis), el derecho comparado plantea soluciones disímiles de bastante envergadura, ad exemplum, los juicios de probabilidad parcial (causalité partielle o causalità razziale), posible (mögliche Kausalitätsprinzip), probabilística (Probabilistic Causation Approach, causalità probabilistica) conexión probable, predictibilidad, o proporcional (Proportional Causation Approach), la causalidad disyuntiva, alternativa, anónima, sospechada, colectiva o conectada, la \responsabilidad colectiva $\bigotimes$ (Ley 25.675 Argentina) o la 'responsabilidad anónima' dándose un grupo presunto de responsables, tomándolos in solidum a todos. En sentido análogo, algunas legislaciones disciplinan presunciones de causalidad cuando de las circunstancias fácticas del caso concreto un comportamiento es idóneo para causar el daño, se presume efectivamente causado por este sin requerir la prueba cierta del nexo, verbi gratia, la idoneidad específica de una planta para producir el daño será apreciada conforme a los detalles concretos de su ejercicio, operaciones, equipo utilizado, naturaleza y concentración de las sustancias liberadas en el medio ambiente, las condiciones atmosféricas, la hora y lugar del daño, y bajo cualquier otra circunstancia que, en su contexto fáctico, pueda proporcionar evidencia a favor o en contra de su ocurrencia, salvo si obtenidas todas las autorizaciones para funcionar, no se encuentra ninguna anomalía en su ejercicio (art. 305 del Decreto legislativo 152/2006, Italia). El \$6 de la Ley alemana del Medio Ambiente (UmweltHG, de 10 de diciembre de 1990) previene la presunción de causalidad cuando la instalación se considera 'apropiada' o 'intrínsecamente adecuada' para generar el daño, en cuyo caso probada la adecuación, compete al presunto autor acreditar que no es su causa o enervar la presunción demostrando su idónea utilización, ausencia de anomalías en su funcionamiento y el cumplimiento de los 'deberes de utilización' $(2, \S 6)$ u otra circunstancia 'apropiada' $(\S 7)$, y la jurisprudencia americana aplica además de las reglas but for test (conditio sine qua non), las relativas al factor sustancial conforme a un test de probabilidad, 'balance de probabilidades' (balance of probabilities), precisándose en el marco de circunstancias fácticas la probable causación del daño o su no ocurrencia (more probable than not, more likely than not), acorde a la preponderancia del hecho (preponderance of the evidence), el criterio more probable than not, "juicio dentro del juicio' (trial within the trial; procès-dans-le-procès) o juicio probabilístico fundado en un conjunto serial de casos tomando las actividades generales y las particulares a apreciar, así como la causalidad alternativa...". Colombia, Corte Suprema de Justicia, Sala de Casación Civil. Proceso 52835-3103-001-2000-00005-01, Sentencia del 16 de mayo de 2011. Magistrado ponente William Namén-Vargas. Disponible en: https://redjusticiaambientalcolombia.files.wordpress. com/2014/06/csj16-mayo2011.pdf. Cfr. Luis Díez-PiCAzo y Ponce de León, Derecho de daños, 338, Civitas, Madrid (1999). Alemania, UmweltHG, Ley del Medio Ambiente, 10 de diciembre de 1990. Disponible en: http://www.gesetze-im-internet.de/bundesrecht/umwelthg/gesamt.pdf

6 Con relación a esta dificultad, en el derecho francés diversos autores citados por Christophe Quézel-Ambrunaz han dicho: "La causalité est une notion qui fait presque consensus au sein de la doctrine française... sur sa difficulté: 'la notion de causalité est une redoutable sirène: elle égare volontiers ceux que sa subtilité séduit et qui cherchent à la pénétrer jusque dans ses mystères intimes'. Il est certain que 'l'analyse de la causalité n'a guère tenté les auteurs français, pénétrés qu'ils étaient de la vanité de leurs recherches face au pragmatisme de la jurisprudence', et l'on déplore ses 'affres', ou ses 'arcanes'. La causalité serait 'le problème le plus complexe de la responsabilité civile', un 'redoutable mystère', une notion 'd'une extrême difficulté', 'toujours irritante', un problème 'insoluble'; 'l'un des champs de discussion les plus difficiles et aussi les plus confus de la doctrine', et 'l'une des questions les plus insaisissables de notre droit'; sa théorisation serait une 'recherche absolument vaine"'. CHRistophe QuÉzeLAmbrunaz, Définition de la causalité dans le droit français, en La causalité dans le droit de la responsabilité civile européenne, Troisième Séminaire du Groupe de Recherche Européen sur la Responsabilité Civile, GRERCA, 26-27 mars 2010, Université de Genève (2010). Disponible en: https://hal.archives-ouvertes.fr/hal-00485806/document 
En Colombia, la jurisprudencia de la Corte Suprema de Justicia en su Sala de Casación Civil ha acogido la teoría de la causalidad adecuada como herramienta para señalar cuándo una actuación ha sido la causa de un daño y, a partir de ello, condenar a su autor a reparar el perjuicio irrogado. Por esta razón, el presente estudio pretende exponer las limitaciones que se le han atribuido a la teoría de la causalidad adecuada que, por fundamentarse en parámetros abstractos como las máximas de la experiencia, el sentido común y la previsibilidad, pueden llegar a enervar la indemnización de ciertos daños que, de acuerdo con la justicia, deberían indemnizarse.

Se demostrará que la inexistencia de una distinción entre causalidad de hecho y causalidad de derecho —o, más propiamente, entre causalidad e imputación objetiva - en el sistema jurídico nacional, ha llevado a que el criterio de la adecuación y, de contera, el parámetro del observador óptimo y la prognosis póstuma sean adoptados como una teoría de la causalidad fáctica y no de la imputación propiamente dicha, que es como, en principio, debería figurar. Ello ha acarreado una serie de inconvenientes, por ejemplo, por solapamiento de las categorías y por reducción al absurdo en lo tocante con la causalidad fáctica.

Por ello, como propuesta, se presentará una teoría que propende por la diferenciación entre una causalidad de hecho y una causalidad de derecho, en aras de determinar acertadamente cuándo se configura la relación causal. Con esta distinción se intenta superar los problemas achacados a la causalidad adecuada, para prevenir los resultados contraintuitivos que se presentan con su aplicación. Para la primera clase de causalidad propuesta - la causalidad de hecho-, se recurrirá al juicio contrafáctico que proporciona la conditio sine qua non; este permitirá afirmar cuándo hay relación causa-efecto de un hecho frente a un daño, desde una perspectiva física o meramente naturalista. En cuanto a la segunda - la causalidad de derecho-, se retomará el juicio de previsibilidad del que echa mano la teoría de la causalidad adecuada para lograr la imputación objetiva de un perjuicio a un agente.

Con esto se intenta exponer un sistema de adecuación causal en materia de responsabilidad civil que ofrezca el remedio más idóneo a las dificultades que hoy se presentan en esta materia, abriendo el debate, a partir de la crítica positiva, a la reformulación de las 
teorías actualmente empleadas. Lo anterior sin perjuicio de una segunda parte de este escrito en la que se analizarán algunos problemas restantes a los que da lugar esta teoría, como la sobredeterminación y la incertidumbre causal.

\title{
I. CAUSALIDAD EN MATERIA DE RESPONSABILIDAD CIVIL. UNA APROXIMACIÓN A LAS DIFERENTES TEORÍAS
}

\author{
El nexo de causalidad en materia de derecho de daños toma su \\ definición de otras ciencias. En efecto, diferentes planteamientos \\ filosóficos, físicos y científicos proporcionan las bases para la \\ construcción del concepto causal en la esfera jurídica7. El primer \\ autor reconocido en adelantar un estudio sistemático sobre esta \\ materia fue Aristóteles; el filósofo griego propuso una tipología \\ causal formada por cuatro tipos de causas, a las cuales denominó \\ causa formal, causa material, causa eficiente y causa final ${ }^{8}$. De todas \\ estas categorías, la causa eficiente es la que nos permite identificar
}

7 Al respecto se ha dicho: "Mientras la causalidad genera una serie de preguntas interesantes en la filosofía (p. ej. la crítica de David Hume (1711-1776) hacia el entendimiento convencional de la necesidad causal), su discusión dentro de la filosofía del derecho se relaciona normalmente con la manera en que dicho concepto ha sido reformulado por la doctrina jurídica, a fin de reflejar ideas e intuiciones relativas a la responsabilidad moral y a las políticas públicas. En el derecho, al igual que en la filosofía moral, el tema de la 'causalidad' está estrechamente ligado con la atribución de responsabilidad o culpa derivada de un incidente o suceso, aunque en un sentido más amplio o empírico de 'causalidad' el incidente o suceso haya sido el producto de un número de acciones y circunstancias más extensas, y quizá infinitas”. BIX H. BRIAN, Diccionario de teoría jurídica, 74, Instituto de Investigaciones Jurídicas, Universidad Nacional Autónoma de México, UNAM, México (2009). Así mismo, el profesor Luis Díez-Picazo y Ponce de León reconoce: "Aunque la utilización del concepto de causa por los juristas haya tenido su origen en consideraciones de orden filosófico, al trasladarlo después a un lenguaje usual, es muy probable que la apreciación causal en materia jurídica se comenzara haciendo de una forma artesanal, de acuerdo con las experiencias de que se disponía”. Luis Díez-Picazo y PonCe de León, Fundamentos de derecho civil patrimonial, tomo V, 359, Editorial Thomson, Civitas Ediciones, Madrid (2007).

8 Sobre este punto, Isidoro H. Goldenberg hace el siguiente aporte: "Es, sin embargo, con Aristóteles que puede situarse el inicio del llamada "causalismo científico". El estagirita requiere el concurso de cuatro causas para la producción de cualquier resultado. Todo efecto, de acuerdo con su pensamiento, ha de ser producido por algo o por alguien (causa eficiente), para algo (causa final), de algo (causa material) y con introducción de algo (causa formal). Se distinguen, de este modo, cuatro géneros de causa: efficiens, finalis, materialis y formalis. La causa material y la formal son causas del ser; la eficiente y la final, causas del devenir". IsidoRO H. GoldenBerg, La relación de causalidad en la responsabilidad civil, 5, Editorial Astrea, Buenos Aires (1984). Cfr. Eric Engle, Aristotelian Theory and Causation: The Globalization of Tort, 2 Gujarat National Law University Law Review, 1, 1-18 (octubre de 2009). Disponible en: http://papers.ssrn.com/sol3/papers.cfm?abstract_id=1424693 
la existencia de una relación causa-efecto entre la actuación de un sujeto y un daño, pues es esta la que predica que "es causa lo que da comienzo al cambio o a la quietud, por ejemplo, el autor de una decisión es la causa de ella, el padre es causa del hijo y, en general,

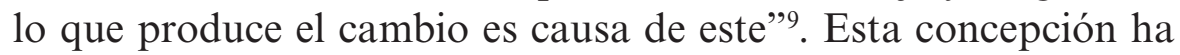
permeado el Derecho. Así, por ejemplo, el profesor Díez-Picazo, al comentar la definición de causa presentada en la Enciclopedia de Denis Diderot y Jean-Baptiste Le Rond d'Alembert expresa: "causa es todo aquello en virtud de cuya eficacia una cosa es; y efecto todo aquello que es en virtud de la eficacia de una causa"10 de donde entonces se colige que la consabida causalidad no es más que "el enlace material entre un hecho antecedente y un resultado (daño), conocido en la doctrina como 'imputabilidad o atribuibilidad objetiva', 'imputatio facti o vínculo material'"'11 que, por lo demás, en su condición de elemento axiológico de la responsabilidad civil, tiene la función de dar respuesta a dos preguntas estructurales: ¿quién debe responder? y ihasta dónde debe responder? ${ }^{12}$

9 Nicola Abbagnano, Diccionario de filosofía, 152, Fondo de Cultura Económica, FCE, México (1987). Cfr. Atilio Aníbal Alterini, Responsabilidad civil, 136-138, $3^{\text {a }}$ ed., Editorial AbeledoPerrot, Buenos Aires (1992).

10 Luis Díez-Picazo y Ponce de León, Fundamentos de derecho civil patrimonial, tomo V, 359, Editorial Thomson, Civitas Ediciones, Madrid (2007). Nicola Abbagnano, en su Diccionario de filosofía, comenta sobre la causalidad: "En su significado más general, la relación entre dos cosas, en virtud de la cual la segunda es unívocamente previsible a partir de la primera. Históricamente, esta noción ha adquirido dos formas fundamentales: 1) la forma de una relación racional, por la cual la cusa es la razón de su efecto que, por lo tanto, es deducible de ella. Esta concepción describe a menudo la acción de la causa como una fuerza que genera o produce necesariamente el efecto; 2) la forma de una relación empírica o temporal, por la cual el efecto no es deducible de la causa, pero es previsible a partir de ella, por la constancia y uniformidad de la relación de sucesión. Esta concepción elimina de la relación causal la idea de fuerza. A ambas formas les es común la noción de la previsibilidad unívoca, esto es, infalible, del efecto, a partir de la causa y por lo tanto de la necesidad de la relación causal". Nicola Abbagnano, Diccionario de filosofía, 152, Fondo de Cultura Económica, FCE, México (1987).

11 Isidoro H. Goldenberg, La relación de causalidad en la responsabilidad civil, 2, Editorial Astrea, Buenos Aires (1984).

12 Sobre este punto, Adriano de Cupis expone: "No menor importancia reviste el establecer la magnitud, o sea, la dimensión o montante, el quantum del daño al que el ordenamiento jurídico atribuye valor de hecho jurídico, uniéndole una reacción propia. Establecida la transmisión de la carga del daño de un sujeto a otro, importa precisar, además, cuánto daño deba experimentar tal transmutación y cuánto daño deba ser eventualmente soportado por el que lo ha sufrido. La determinación del quantum respondeatur tiene, precisamente, tanta importancia como la del determinar al an respondeatur, porque, de poco serviría tener derecho al resarcimiento si fuese mínima la entidad del daño a resarcir. En consecuencia, importa enormemente precisar los límites cuantitativos dentro de los que el daño asume sentido jurídico. (...) El contenido jurídico del daño está, ante todo, en función de la relación de causalidad entre el hecho productor del daño y el daño, es decir, que para fijar el montante del daño que 
Ya lo señalaba Luis Díez-Picazo, para quien:

el concepto de causa y el de causalidad se utilizan en materia de responsabilidad civil, para tratar, básicamente, de dar respuesta a dos tipos de problemas: el primero es encontrar alguna razón por la cual el daño puede ligarse con una determinada persona, de manera que se pongan a cargo de esta, haciéndola responsable, las consecuencias indemnizatorias, para lo cual se utiliza el concepto de causa en el art. 1902 CC [español: 'El que por acción u omisión causa daño a otro, interviniendo culpa o negligencia, está obligado a reparar el daño causado', análogo del art. 2341 de la Codificación colombiana] al imponer el deber de indemnizar a 'el que causa daño a otro'; en segundo lugar, se trata de relacionar, a la inversa de lo que hacíamos anteriormente, al daño con la persona, pues el precepto, remarcando el uso de la palabra causa, dice que se indemniza 'el daño causado't3.

\section{En similar sentido, Ramón Daniel Pizarro afirma que la causali- dad brinda: "los parámetros objetivos indispensables para calibrar}

debe reprimirse jurídicamente, se requiere, en primer lugar, establecer los límites dentro de los que el daño pueda considerarse causado por un hecho humano provisto de los atributos exigidos por la ley con fines de responsabilidad”. Adriano de CuPIs, El daño. Teoría general de la responsabilidad civil, 245-246, Ángel Martínez-SARrión, trad., Bosch, Casa Editorial, Barcelona (1970). Sobre el particular, Juan Manuel Prevot comenta: "La causalidad cumple en el Derecho de la Responsabilidad Civil dos funciones: 1) Una relativa a la imputación del hecho dañoso a su autor o, si se prefiere, tendiente a la individualización del responsable, denominada por buena parte de la doctrina autoral italiana como 'causalidad material' y, 2) Otra, consistente en determinar el contenido de la obligación resarcitoria, conocida como 'causalidad jurídica'. Una cosa es, entonces, emplear la causalidad a los fines de imputar el evento lesivo a un sujeto (causalidad como requisito autónomo de la responsabilidad), y otra muy distinta es utilizar la causalidad para determinar la medida de la reparación (causalidad como complemento). En el primer caso, se responde al interrogante, ¿quién causó el daño? (etapa del an respondeatur). Mientras que en el segundo, se responde a la pregunta, ¿cuánto debe pagar el responsable? (etapa del quantum respondeatur). Esta doble función que cumple la causalidad en el ámbito de la responsabilidad civil, junto a las diversas formas que forzosamente adquiere la misma, según el ámbito o fattispecie en que opere, imposibilitan todo intento de reconstrucción unitaria". JuAn Manuel Prevot, El problema de la relación de causalidad en el derecho de la responsabilidad civil, 15 Revista Chilena de Derecho Privado, 143-178, 146 (diciembre de 2010). Disponible en: http://www.scielo.cl/scielo.php?pid=S0718$80722010000200005 \&$ script $=$ sci_arttext

13 Luis Díez-Picazo y Ponce de León, Fundamentos de derecho civil patrimonial, tomo V, 357, Editorial Thomson, Civitas Ediciones, Madrid (2007). En igual sentido, Marcelo López-Mesa señala: "Para que persona pueda ser tenida como civilmente responsable por un acto ilícito dañoso, resulta imprescindible que el daño pueda ser objetivamente atribuido a la acción u omisión de un hombre o al hecho de una cosa -imputatio facti o relación de causalidad. En palabras del profesor [André] Brun, 'responsabilidad civil y causalidad son consustanciales". Félix A. Trigo-Represas \& Marcelo López-Mesa, Tratado de responsabilidad civil, 360, $2^{\mathrm{a}}$ ed., Editorial La Ley, Buenos Aires (2011). Para Philippe Le Tourneau, "Racionalmente, la responsabilidad civil supone un nexo de causa a efecto entre el perjuicio y el hecho dañino. Este último debe haber sido causa generadora del daño, así como la cosa debe haber desempeñado un papel activo en la producción del daño. Los términos de los artículos 1382 [Code Civil Français: 'Tout fait quelconque de l'homme', qui cause à autrui un dommage, oblige 
la extensión del resarcimiento, mediante un régimen predeterminado de imputación de consecuencias. A través de ella se determina hasta dónde el sistema vigente quiere que el autor material responda por sus actos evitándose la elongación excesiva del perjuicio y el enriquecimiento consiguiente del damnificado"14.

De esta forma, se tiene que la causalidad permite al demandante determinar contra quién debe dirigir su pretensión indemnizatoria y cuáles son los daños que tiene derecho a que le sean reparados por ese agente dañador. Así mismo, la comprobación de la existencia de un nexo de causal entre la actuación de un sujeto y un menoscabo injustificado en los derechos de una persona permite al juzgador, a la hora de un juicio de responsabilidad civil, imponer la condena única y exclusivamente al causante del daño y obligarlo a resarcir solamente los perjuicios que ocasionó con su conducta. Finalmente, desde la perspectiva del acusado de haber irrogado un daño, la causalidad le permite ejercer su defensa para que ante la ausencia de esta fracase la pretensión indemnizatoria dirigida en su contra ${ }^{15}$. De allí se colige también que la causa supone un ele-

celui par la faute duquel il est arrivé à le réparer'] y siguientes justifican este principio: todos exigen que el hecho, la cosa, el animal o el edificio causen el daño. Solo el perjuicio directo podrá ser reparado, porque solo él está ligado por ese nexo de causa a efecto al acto imputado al responsable, el hecho generador". Philippe Le Tourneau, La responsabilidad civil, 78, Legis Editores, Bogotá (2010). En el ámbito colombiano, Álvaro Pérez-Vives señala: "Para que surja la obligación de reparar un daño es preciso que entre este y la culpa exista un vínculo que permita afirmar que el primero es efecto de la segunda. En otras palabras, que la culpa haya causado el perjuicio". Álvaro Pérez-Vives, Teoría general de las obligaciones, vol. II, parte primera, $4^{\mathrm{a}}$ ed., 327, Alberto Tamayo-Lombana, rev. y actual., Ediciones Doctrina y Ley Ltda., Bogotá (2011).

De igual manera, el profesor Arturo Solarte señala: "Para que se pueda reclamar la reparación del daño antijurídico debe existir una relación de causalidad entre el hecho que lo ha provocado y la conducta de quien se dice fue su autor, sea que esta haya consistido en una acción o, simplemente, en una omisión". Arturo Solarte-Rodríguez, Los actos ilícitos en el Derecho Romano, 107 Vniversitas, 691-746, 711 (2004). Disponible en: http://www.javeriana. edu.co/juridicas/pub_rev/documents/18solarte.pdf

14 Ramón Daniel Pizarro, Responsabilidad civil por riesgo creado y de empresa. Contractual y extracontractual, tomo I, 89, Editorial La Ley, Buenos Aires (2006). En otro de sus escritos, el mismo autor señala: "Dentro del ámbito de la responsabilidad civil, la relación de causalidad asume una doble función, de singular importancia: a) permite determinar, con rigor científico, cuándo un resultado dañoso es material u objetivamente atribuible a la acción del sujeto determinado; b) brinda, al mismo tiempo, los parámetros objetivos indispensables para calibrar la extensión del resarcimiento, mediante un régimen predeterminado de imputación de consecuencias. Este es uno de los grandes pilares sobre los que se edifica el moderno derecho de daños, que debe orientar sus esfuerzos hacia una justa e integral reparación de todo detrimento injustamente causado". Ramón Daniel Pizarro, Causalidad adecuada y factores extraños, en Derecho de daños. Homenaje al profesor Jorge Mosset-Iturraspe, 255-256, Félix A. Trigo-Represas \& Rubén Stiglitz, dirs., La Rocca, Buenos Aires (2000).

15 Al respecto, el maestro Fernando Hinestrosa explica: "En presencia de un quebranto patrimo- 
mento moralizador: permite hacer patente una exigencia de justicia correctiva en la responsabilidad civil, pues impone la obligación de indemnizar solamente a quien ha dado lugar a la interacción injusta, del modo que lo sugieren las concepciones contemporáneas de esta forma de justicia. Puesto en otros términos, la causalidad evita que el débito indemnizatorio se disperse en cabeza de cualquier sujeto y lo concentra en cabeza del agente dañador, con lo que cristaliza una exigencia de justicia $-\mathrm{y}$, más específicamente, de justicia correctiva- en la responsabilidad.

El inconveniente, con todo, es que a la utilidad e importancia práctica de la causalidad se suma una dificultad ostensible en su análisis y determinación. Ciertamente, como se ha expuesto a lo largo del texto, por sencillo que pareciera, en principio, adelantar el análisis de causalidad, lo cierto es que las ciencias jurídicas están aún lejos de encontrar una teoría que responda satisfactoriamente tales interrogantes ${ }^{16}$. Como lo resalta el profesor Jorge Santos-

nial o moral salta a la vista la necesidad de buscar su origen, indagar por el responsable. Si se trata de un daño que la propia víctima maliciosa o descuidadamente se ocasionó, mal podría ella achacarlo a persona distinta, o como se diría en lenguaje familiar, 'buscar el ahogado río arriba'. Si el perjuicio lo causó persona distinta del demandado y por la que no está llamado él a responder, a ese tercero deberá acudir la víctima y no a quien nada tiene qué ver en el asunto. Por último, si la ocurrencia provino de fuerzas naturales o sociales anónimas e irresistibles, la víctima habrá de padecer su mala suerte sin posibilidad de descargar su quebranto sobre persona determinada". Fernando Hinestrosa, Curso de obligaciones (conferencias), 358, $2^{\mathrm{a}} \mathrm{ed}$. mimeo, Facultad de Derecho de la Universidad Externado de Colombia, Bogotá (1961). De esta forma, una causa extraña - sea esta por la intervención de un tercero (hecho de un tercero), por la propia aportación de la víctima en la producción del daño (hecho de la víctima) o por una causa ajena que revista las características del caso fortuito o fuerza mayor, dependiendo de su magnitud - puede aminorar o suprimir el vínculo causal de la conducta del agente señalado como dañador con el perjuicio. Para el caso colombiano, Juan Pablo Cárdenas-Mejía expone: "El Código Civil colombiano no consagra expresamente la causa extraña como factor de exoneración de responsabilidad, sino que se refiere a la fuerza mayor y al caso fortuito. Sin embargo, la jurisprudencia y doctrina se refieren a la causa extraña como eximente de responsabilidad. Históricamente, la distinción entre causa extraña y fuerza mayor surge de la redacción del Código Civil francés que hace referencia a dichos conceptos. Aunque la noción de causa extraña se basa en la redacción de dicho Código, ha sido recogida por nuestra doctrina en la medida en que agrupa aquellos elementos que exoneran de responsabilidad y que son ajenos al deudor o a la persona a la que se le pretende imputar la responsabilidad. Tradicionalmente, se han señalado como casos de causa extraña la fuerza mayor o el caso fortuito, el hecho de un tercero o el hecho de la víctima". Juan Pablo Cárdenas-Mejía, Causa extraña como eximente de responsabilidad, en Derecho de las obligaciones, tomo II, vol. I, 349, Marcela Castro de Cifuentes, coord., Ediciones Uniandes, Editorial Temis (2010). Sobre el mismo tema, se pueden consultar: Ramón Daniel Pizarro, Causalidad adecuada y factores extraños, en Derecho de daños. Homenaje al profesor Jorge Mosset-Iturraspe, 255 y ss., FÉLIX A. Trigo-Represas \& Rubén Stiglitz, dirs., La Rocca, Buenos Aires (2000). María MedinaALcoz, La culpa de la víctima en la producción del daño extracontractual, Editorial Dykinson, Madrid (2003).

16 Javier Tamayo-Jaramillo afirma sobre esta problemática: "la doctrina pareciera resignarse 
Ballesteros, "a pesar de su presencia ineludible, sin embargo, y no obstante constituir esa relación el enlace entre el hecho causante del ilícito y el detrimento de la reparación, no siempre su configuración jurídica ha obedecido a criterios uniformes o patrones definidos, al contrario de lo sucedido con los otros dos factores integrantes de la responsabilidad civil, es decir, la culpa y el daño"17. Para dar una idea del laberinto que representa desentrañar el nexo de causalidad en materia de responsabilidad civil, resulta ilustrativo un difundido ejemplo doctrinal. Supóngase la siguiente situación:

Leo en el diario ABC: $\nabla U n$ perro cae al vacío y provoca varias muertes consecutivas. Una cadena de sucesos trágicos se sucedió en el barrio bonaerense de Caballito a partir del momento en que un perro cayó accidentalmente desde un decimotercer piso. Cachi, que así se llamaba el animal, fue a golpear en la cabeza de Marta Fortunata, de setenta y cinco años, que caminaba despreocupada por el lugar. Como consecuencia del impacto, la anciana murió de forma instantánea. Seguidamente, una rueda de curiosos se comenzó a formar en torno al cadáver. El corro desbordó pronto la acera y comenzó a ganar parte a la calzada, donde el tráfico se desarrollaba a gran velocidad. En ese momento, un autobús alcanzó de lleno a Edith Solá, de cuarenta y seis años, quien murió en el lugar después de haber sido arrastrada varios metros por el vehículo. Cuando el estupor de los presentes ante este trágico suceso no habia desaparecido, frente al escenario de los hechos, un hombre que no fue

ante la imposibilidad de dilucidar con claridad el problema del nexo causal y encontrar una teoría que lo solucione satisfactoriamente. Al respecto, Geneviève Viney expresa: 'Numerosos juristas de todos los países han puesto seriamente en duda la utilidad de las tentativas de solución científica del nexo de causalidad. En Francia, [Georges] Ripert por ejemplo, ha tomado posición muy clara en favor de una actitud puramente pragmática al respecto, y en ese sentido expresa 'la jurisprudencia haría bien si rechaza el entregarse al análisis de causalidad porque esta ha suscitado brillantes estudios doctrinales que no han aportado ninguna solución a este problema general que es tal vez insoluble'. Y los señores [Henri, Léon, Jean] Mazeaud, de su lado, después de haber recordado que la causalidad debe ser cierta, lo que implica, dicen ellos, que el daño es la consecuencia necesaria del hecho percibido, confiesan que es difícil dar más precisión sobre la noción de daño indirecto y se pliegan a la opinión de [René] Demogue para quien 'se trata de una cuestión de buen sentido más que de ciencia... que ha agotado las paciencias más probas'. Estos autores se limitan a dar ejemplos sin pretender alcanzar una noción general. Boris Starck va más lejos aún, puesto que afirma sobre este punto que 'todo ensayo de razonamiento científico se vuelve ineficaz', lo que parece igualmente ser la opinión de [Paul] Esmein"'. Javier Tamayo-Jaramillo, Tratado de responsabilidad civil, tomo I, 380, Legis Editores, Bogotá (2007).

17 Jorge Santos-Ballesteros, Responsabilidad civil, tomo I, 376, $3^{\mathrm{a}}$ ed., Editorial Temis, Pontificia Universidad Javeriana, Bogotá (2013). 
identificado sufrió un ataque cardíaco y murió minutos después, en el interior de la ambulancia que lo trasladaba a un hospital ${ }^{18}$.

Ante esta cadena de eventos infortunados, aflora la duda sobre la causa que los ha generado y quién será el llamado a responder. Dependiendo de la teoría jurídica de determinación causal que se adopte, ya sea la teoría de la equivalencia de las condiciones, la teoría de la causa próxima, la teoría de la causa eficiente, la teoría de la causa adecuada, o se opte por la teoría de la imputación objetiva, la decisión sobre quién deberá soportar la reparación del perjuicio podrá variar, como se verá en adelante.

Para determinar la causa de un daño, la teoría de la equivalencia de las condiciones utiliza un juicio contrafáctico, en el cual se parte de la supresión de los eventos considerados como posibles causas del perjuicio, para evaluar si - a pesar de la falta de alguno de estos- el daño subsiste. Si la respuesta al realizar esta operación es negativa (la consecuencia no desaparece, a pesar de la omisión de la posible causa), se descarta esta posible causa; por el contrario, si la respuesta es positiva (la consecuencia desaparece por la omisión de la posible causa), se tiene a esta por causa del daño y, además, se le tiene en iguales condiciones que todos los demás que cumplan el test, considerándolas a todas conditio sine qua non del perjuicio irrogado, por cuanto "faltando cualquiera de ellos, el daño no se habría producido"19 20. Es, en esencia, la estructura del juicio contrafáctico típico.

Para mayor claridad se examina el caso expuesto anteriormente a la luz de la teoría presentada, para ejemplificar lo que sería el resultado de un juicio de causalidad bajo esta concepción. Ante la muerte de la señora, es evidente que, si se suprime la caída del perro

18 Mariano Yzquierdo-Tolsada, Sistema de responsabilidad civil, contractual y extracontractual, 187, Editorial Dykinson, Madrid (2001). Un perro cae al vací y provoca tres muertes consecutivas, $A B C$, lunes 24 de octubre de 1988. Disponible en: http://hemeroteca.abc.es/nav/Navigate. exe/hemeroteca/madrid/abc/1988/10/24/089.html

19 Philippe Le Tourneau, La responsabilidad civil, 79, Legis Editores, Bogotá (2010).

20 Sobre la teoría de la equivalencia de las condiciones, Luis Díez-Picazo explica: "Cuando un resultado aparece tras un conjunto de condiciones, el método experimental exige suprimir mental o empíricamente cada una de ellas. En este sentido, causa es la condición sine qua non del daño, es decir aquel de los elementos o las condiciones que, si hubieran faltado el resultado dañoso no se hubiera producido. Si se quita la causa, desaparece la consecuencia (sublata causa tollitur effectus)". Luis Díez-Picazo y Ponce de León, Fundamentos de derecho civil patrimonial, tomo V, 360, Editorial Thomson, Civitas Ediciones, Madrid (2007). 
desde lo alto, se arriba a la conclusión de que esta es conditio sine qua non de esta eventualidad, comoquiera que a falta de perro, no habría resultado dañoso.

Pero de otro lado, si se suprime el hecho de que quien habita en el apartamento del decimotercer piso tuviera esa mascota, lo cierto es que el resultado dañoso tampoco habría ocurrido, lo que haría que el hecho de vivir en ese piso con una mascota se erija también en causa del daño. Más aún, si realiza el juicio contrafáctico en relación con la existencia de un edificio de esa altura, la conclusión es que en ausencia del mismo la muerte no hubiera tenido lugar; el constructor sería entonces también detonante causal del hecho. Se tiene entonces, a partir de la teoría de la equivalencia de las condiciones, que el nexo causal se extiende ad infinitum, pues las condiciones para la producción del hecho dañoso se equiparan a las causas de daño ${ }^{21}$, lo que da lugar a respuestas inequitativas pues expande la órbita de responsabilidad a agentes que, por la lejanía con el hecho dañoso, carecen del vínculo necesario con el daño como para que sean condenados a repararlo, tal como sería el caso del constructor del edificio ${ }^{22}$.

En este punto se asientan las principales críticas que se han esgrimido en contra de esta teoría. Jurídicamente, resulta inacep-

21 Sobre la diferencia que debe haber entre condiciones y causas de un daño, que no se logra al aplicar la teoría de la equivalencia de las condiciones, Ramón Daniel Pizarro expone: "La condición es un mero antecedente del resultado que produce. Ordinariamente, un efecto es producido por múltiples condiciones, que en conjunto lo provocan. El derecho, como regla general, no atribuye autoría material del daño, ni responsabiliza a un sujeto por el mero hecho de haber puesto una condición, aunque esta pueda ser necesaria para su producción, ya que en caso de no haberse producido, el efecto no se habría desencadenado. Es preciso, para ello, que la condición asuma especial entidad, por ser adecuada para producir ese resultado, en cuyo caso se eleva a la categoría de causa jurídica, generadora del detrimento. Así concebida la cuestión, puede afirmarse que 'si bien la causa es siempre una condición de daño, no toda condición es causa'. Dentro de las muchas condiciones que pueden contribuir a un resultado, encontramos a la ocasión, que favorece o torna viable la actuación de la verdadera causa del daño, pues permite, facilita o potencia su aptitud causal. En principio no se responde por el mero hecho de haber facilitado o provocado la ocasionalidad del daño. Quien invita a un amigo a practicar golf, no responde si en ocasión del juego, este es lesionado por la pelota lanzada al jugador, o es agredido con motivo de una discusión con otro competidor". RAMÓN DANIEL Pizarro, Responsabilidad civil por riesgo creado y de empresa. Contractual y extracontractual, tomo I, 91, Editorial La Ley, Buenos Aires (2006).

22 Adicionalmente, el profesor Jorge Suescún-Melo pone de presente: "se le reprocha su falta de elasticidad, pues exige, en caso de concurrencia de culpas con la víctima, dividir por partes iguales la indemnización, pues recuérdese que esta doctrina considera que todas las causas concurren del mismo modo a la producción del daño, lo que puede estar en oposición con la equidad”. Jorge Suescún-Melo, Derecho privado. Estudios de derecho civil y comercial contemporáneo, tomo I, 150, 2ª ed., Legis Editores, Bogotá (2003). 
table expandir ad nauseam la relación causal entre un hecho y un resultado $^{23}$. Si bien la teoría de la equivalencia de las condiciones permite materialmente determinar un vínculo causa-efecto, lo cierto es que lo hace desde un punto de vista material o natural; desde el derecho de daños no es equitativo el criterio que ella propone para imputar a alguien una condena a reparar los perjuicios sufridos por otra persona $^{24}$. Al respecto, Philippe Le Tourneau hace la siguiente reflexión: "Si en otras épocas esta teoría podría permitir una reparación equitativa de los daños, en una economía esencialmente agrícola y artesanal, ya eso no ocurre hoy en día. El progreso téc-

23 Con todo, hay quienes también critican esta teoría por dejar impune al autor de ciertos daños. Así lo hace Luis Díez-Picazo para quien, "la fórmula de la condición snq [sine qua non] peca también, sigue diciendo [João de Matos] Antunes Varela, además de por exceso, por defecto, ya que no comprende dentro del nexo de causalidad, ciertos daños que sería injusto no poner a cargo del autor de un hecho, como ocurre en la hipótesis que ha sido denominada de causalidad acumulativa o alternativa o en los daños causados por miembros indeterminados de un grupo que efectúa disparos o lanza cócteles molotov, sin que ninguno de ellos, aisladamente considerado, se pueda decir que sin él no hubiera ocurrido el daño sufrido por la víctima, no es causante del daño de manera que habría que entender que no debe ser considerado responsable del daño en el sentido de la sqn del daño verificado. Y, al revés, si, como ocurre en el parágrafo 830 del BGB [Bürgerliches Gesetzbuch, Código Civil alemán, ‘§ 830 Mittäter und Beteiligte. (1) Haben mehrere durch eine gemeinschaftlich begangene unerlaubte Handlung einen Schaden verursacht, so ist jeder für den Schaden verantwortlich. Das Gleiche gilt, wenn sich nicht ermitteln lässt, wer von mehreren Beteiligten den Schaden durch seine Handlung verursacht hat. (2) Anstifter und Gehilfen stehen Mittätern gleich'], se considera que hay autoría múltiple, el daño se está imputando a persona o personas que no lo han causado". Luis Díez-Picazo y Ponce De León, Fundamentos de derecho civil patrimonial, tomo V, 361 , Editorial Thomson, Civitas Ediciones, Madrid (2007). Alemania, Bürgerliches Gesetzbuch, Código Civil, 24 de agosto de 1896. Disponible en: http://www.gesetze-im-internet.de/bgb/ BJNR001950896.html, http://www.gesetze-im-internet.de/englisch_bgb/index.html\#gl_p3448

24 En palabras de Adriano de Cupis, "La objeción que se ha formulado a la teoría de la conditio sine qua non es que, mediante ella, el concepto de causa y, por ende, la responsabilidad, se extienden excesivamente. Indudablemente es necesario que el hecho humano sea condición del daño, pero se desplaza el problema a determinar un quid posterior que establezca los límites razonables de la responsabilidad". Adriano de CUPIS, El daño. Teoría general de la responsabilidad civil, 256, Ángel MartíneZ-SARrión, trad., Bosch, Casa Editorial, Barcelona (1970). Con igual criterio, Atilio Aníbal Alterini señala: "Sutil y vigorosa es la ironía que dedicó [Karl] Binding a esta teoría, luego de afirmar que según ella todo el mundo es culpable de todo: correspondería castigar como coautor de adulterio no solo al varón que yace con la mujer casada con otro hombre, sino también al carpintero que hizo la cama". ATILIo ANíbal Alterini, Responsabilidad civil, 144, 3 ed., Editorial Abeledo-Perrot, Buenos Aires (1992). El profesor Jorge Santos-Ballesteros trae a colación el comentario que sobre el particular hace [Jorge] Peirano [Facio], para quien "aplicada rigurosamente la teoría de la equivalencia de condiciones, 'tiende a ensanchar en forma exagerada el concepto de causa hasta el punto de hacer de esta noción una idea reñida con el sentido común y con el concepto vulgar de justicia. Suponiendo que en un caso dado concurrieran a producir cierto evento una condición y un caso fortuito, habría que imputar el caso fortuito a quien ha puesto una sola de las condiciones, lo cual es contrario a todo principio ético-jurídico y también el buen sentido"'. JORGE Santos-Ballesteros, Responsabilidad civil, tomo I, 393, 3ª ed., Editorial Temis, Pontificia Universidad Javeriana, Bogotá (2013). 
nico, que permite manejar las fuerzas naturales considerables, el desarrollo del maquinismo, las interacciones más frecuentes de las actividades humanas, a veces provocan consecuencias en las que es imposible determinar la parte de cada uno de los intervinientes y cuya amplitud está sin común medida con el papel propio de cada uno de ellos. En fin, para la determinación del nexo de causalidad entre el hecho dañino y sus consecuencias mediatas, necesarias para calificarlas directas, la equivalencia de las condiciones conduce a considerar que permanecen directos y reparables los daños demasiado alejados del hecho generador y, para decirlo de una vez, cuyo nexo con este es puramente hipotético. El problema mayor de la teoría explota aquí: esta no permite fijar cómodamente un límite a la extensión de la responsabilidad"25.

En suma, la respuesta que ofrece la equivalencia de las condiciones es una respuesta insuficiente para el Derecho. Ciertamente, el criterio de esta teoría, cuando es empleado como único test para determinar la relación de causalidad, no ofrece una respuesta satisfactoria, comoquiera que supone un regreso al infinito en el que la causa de la causa, es la causa del mal causado. Esto no quiere decir, en cualquier caso, que sea un criterio erróneo. Para dilucidar la causa desde una perspectiva física o naturalista, la equivalencia de las condiciones o test sine qua non reviste gran utilidad, ya que ofrece una verificación muy certera, al menos en el plano de la acción — pues en el caso de la omisión ofrece dificultades- Tal vez requiere un complemento jurídico que permita delimitar el regreso al infinito, como se expondrá en un segmento ulterior.

Ahora bien, ante la falta de una respuesta satisfactoria desde la teoría de la equivalencia de las condiciones, se han postulado diversas construcciones doctrinarias que intentan presentar diferentes criterios para solucionar la vis expansiva que la conditio sine qua non inconvenientemente proporciona al adelantar el juicio de causalidad en materia de responsabilidad civil.

Así ha surgido, por ejemplo, la teoría de la causa próxima, una construcción teórica que, aunque cronológicamente anterior, presenta un criterio que permite escoger entre las condiciones que producen un daño, una de ellas como única causa del mismo. Para

25 Philippe Le Tourneau, La responsabilidad civil, 81, Legis Editores, Bogotá (2010). 
la causa próxima, únicamente existe nexo de causalidad, a los ojos de la responsabilidad civil, entre el daño y el último hecho que lo precedió $^{26}$. El juicio que se realiza cuando se escoge esta teoría para desentrañar la relación de causalidad consiste en seleccionar, entre las múltiples condiciones que dieron lugar al perjuicio, la que cronológicamente lo antecedió - esto es, la inmediatamente anterior al resultado dañoso-, de esta manera, se evita entrar a hacer juicios ulteriores que den resultados inciertos y que impliquen en términos de Francis Bacon, autor de la misma, una tarea infinita ${ }^{27}$.

La solución que a la luz de esta teoría se daría al caso propuesto precedentemente, resulta relativamente sencilla: la causa de la muerte de la señora es el golpe que le propinó el perro al caer sobre su humanidad. A eso se reduce el estudio de la causalidad cuando de causa próxima se trata.

Aunque es evidente lo efectiva que resulta esta teoría para individualizar la causa de un daño, no está libre de reparos. Mariano Yzquierdo-Tolsada señala: "a la dificultad de establecer cuál ha sido la condición última en un suceso, se añade que no siempre el antecedente temporal más próximo en la cadena causal es el determinante. El concepto de inmediatez ha de tener, por lo tanto, un sentido más lógico que cronológico" 28 .

Por estas razones, que evidencian lo inequitativa que la aplicación de esta construcción teórica resulta en muchos casos, no logró

26 Se ha dicho que de acuerdo a esta teoría, de origen angloamericano, "la auténtica causa sería la proximate cause y al elegir esta habría que rechazar todas las que fueran too remote cause. En esta doctrina, si hubiera condiciones sucesivas que todas ellas son causa de los daños, solo debería utilizarse la causa más próxima”. Íñigo NaVArro-MendizÁbal \& Abel B. Veiga-Copo, Derecho de daños, 191, Editorial Thomson Reuters, Civitas, Madrid (2013). Sobre la aplicación práctica de esta teoría a un caso concreto, se puede ver: New York Court of Appeals. Palsgraf v. Long Island Railroad Co., 248 N.Y. 339, 162 N.E. 99 (N.Y. 1928), decided May 29, 1928. Disponible en: http://www.law.berkeley.edu/files/Palsgraf_NYCA.pdf

27 Sobre la teoría de la causa próxima, el profesor Gerardo Ortiz-Gómez afirma: "fue expuesta por Francis Bacon en su obra Maxims of Law, publicada en el siglo XVI; es decir, fue planteada con mucha anterioridad a la teoría de la equivalencia de condiciones. La máxima elaborada por Bacon señala: "Sería para el derecho una tarea infinita juzgar las causas de las causas y las acciones de las acciones de unas sobre las otras: por eso se contenta con la causa inmediata y juzga los actos desde ese punto de vista sin remontarse a un grado superior"; así las cosas, solo el hecho más próximo en tiempo al daño es el causante de este". Gerardo OrTiz-Gómez, El nexo causal en la responsabilidad civil, en Derecho de las obligaciones, tomo II, vol. I, 322, Marcela Castro de Cifuentes, coord., Ediciones Uniandes, Editorial Temis (2010).

28 Mariano Yzquierdo-Tolsada, Sistema de responsabilidad civil, contractual y extracontractual, 191, Editorial Dykinson, Madrid (2001). Sobre las objeciones formuladas a esta teoría: FéLIX A. Trigo-Represas \& Marcelo López-Mesa, Tratado de responsabilidad civil, 416-417, $2^{\mathrm{a}}$ ed., Editorial La Ley, Buenos Aires (2011). 
asentarse ni alcanzar mayor influencia en la doctrina ${ }^{29}$, lo que dio paso a nuevas teorías jurídicas que han obtenido mayor aceptación, al impregnar la jurisprudencia de diversas latitudes.

Es el caso, por ejemplo, de la teoría de la causa eficiente que, como dice Jorge Suescún-Melo, "ha tenido el favor de un sector importante de la doctrina y de la jurisprudencia nacionales recientes" ${ }^{30}$. Para esta formulación doctrinaria "no interesa ya el acontecimiento que ha precedido inmediatamente al daño, sino que hay que establecer su condición causal según el grado de eficiencia en el resultado (causa efficiens), en oposición al principio de indiferencia de las condiciones sustentado por la teoría de la conditio sine qua non"31.

La causa eficiente prescinde entonces de factores cronológicos; no resulta relevante para este juicio de causalidad lo cercanos o alejados en el tiempo que estén el hecho y el daño para el establecimiento del nexo causal. "Ella eleva a la categoría de causa en sí, a la condición más activa en la producción del resultado. Trata de encontrar, dentro del amplio concurso de condiciones que intervienen en la generación de un resultado, una que, en razón de su intrínseco poder de producción del fenómeno que se aprecia como tal resultado, recibe la calificación preponderante de ser considerada su causa, lo que importa distinguir, tanto cualitativa como cuantitativamente, una condición de las demás"32.

De ahí que, al estudiar la relación de causalidad, se deba diferenciar entre la causa, la condición y la ocasión. La primera - es decir, la causa - es aquella que ha contribuido de manera prevalente a la producción del daño. Por otro lado, la condición es aquella que gesta el entorno necesario para que la causa produzca el resultado, el cual está intrínsecamente en capacidad de producir. Por último,

29 Santos-Ballesteros señala: "la tesis de la causa inmediata o causa próxima no es admitida por la generalidad de la doctrina, por la injusticia evidente que encierra su formulación, dado que de aplicarse, daría lugar a atribuir consecuencias dañosas a actos que en sí mismos no tienen la aptitud para producir un resultado, o no atribuirlas a los que sí la tienen, al faltar la correspondencia necesaria que debe existir entre uno y otro de los extremos de la responsabilidad, pues la disposición cronológica no se corresponde siempre con la causal o lógica que debe presidir este análisis". Jorge SAntos-Ballesteros, Responsabilidad civil, tomo I, 396, $3^{\text {a }}$ ed., Editorial Temis, Pontificia Universidad Javeriana, Bogotá (2013).

30 Jorge Suescún-Melo, Derecho privado. Estudios de derecho civil y comercial contemporáneo, tomo I, 161, $2^{\mathrm{a}}$ ed., Legis Editores, Bogotá (2003).

31 Isidoro H. Goldenberg, La relación de causalidad en la responsabilidad civil, 27, Editorial Astrea, Buenos Aires (1984).

32 Félix A. Trigo-Represas \& Marcelo López-Mesa, Tratado de responsabilidad civil, 418, $2^{\mathrm{a}}$ ed., Editorial La Ley, Buenos Aires (2011). 
la ocasión favorece la producción del daño pues es prescindible para producirlo ${ }^{33}$.

Así, concretando la referencia teórica en el ejemplo que se ha venido trabajando, se puede decir que la causa eficiente para la muerte de la señora es el golpe que perro le propinó al caer. Que la caída fuese de un decimotercer piso es una condición de este daño, pues proporciona la altura necesaria para que el impacto tenga la magnitud suficiente para producir el efecto, pero por sí sola no tiene esa potencialidad. Como ocasión se puede catalogar el hecho de que la señora estuviese caminando para ir a algún lugar: esta actividad propicia que se irrogue el daño, aunque no sea necesaria para su realización.

Aunque el criterio proporcionado por la teoría de la causa eficiente parece suficiente e idóneo para postularse como el juicio de causalidad a seguir por los tribunales, se le han hecho múltiples críticas. Isidoro H. Goldenberg observa: "cuando se trata de establecer en la práctica la pauta que permita seleccionar entre las diversas condiciones de un resultado la más eficiente o la más preponderante, se advierte con nitidez la fragilidad de estas teorías. En efecto, la imposibilidad de escindir materialmente el resultado, de suyo indivisible, para atribuir a una condición per se un poder causal decisivo, hace caer dichas construcciones teóricas en un empirismo que las despoja de todo rigor científico"34.

Si bien esta teoría ha ejercido una fuerte influencia en la jurisprudencia colombiana ${ }^{35}$, no ha sido la tesis con más acogida. En

33 Así lo señala Suescún-Melo, para quien "La causa eficiente es la causa propiamente dicha, es decir, responde a la pregunta: ¿Por quién fue hecho el daño? Y puede definirse como aquello que por su acción produce alguna consecuencia. La condición, en cambio, no produce el efecto sino simplemente permite a la causa eficiente producirlo; descarta, si se quiere, un obstáculo permitiendo así la acción de la causa eficiente. La ocasión no hace más que favorecer el juego de la causa eficiente y en ningún modo es necesaria para la producción del daño". JORGE Suescún-Melo, Derecho privado. Estudios de derecho civil y comercial contemporáneo, tomo I, 162, 2 ${ }^{\mathrm{a}}$ ed., Legis Editores, Bogotá (2003).

34 Isidoro H. Goldenberg, La relación de causalidad en la responsabilidad civil, 29, Editorial Astrea, Buenos Aires (1984). Félix A. Trigo-Represas \& Marcelo López-Mesa, Tratado de responsabilidad civil, 419-421, 2a ed., Editorial La Ley, Buenos Aires (2011).

35 Suescún-Melo, en su obra publicada en 2003, afirmaba: "la jurisprudencia nacional ha adoptado esta teoría donde emplea, incluso, la misma terminología. En efecto, en diversos fallos han subrayado la necesidad de distinguir, de entre los hechos que intervienen en la producción de un daño, 'aquellos que han sido 'causa generadora' y aquellos que solamente han sido la 'ocasión". Por su parte, sentencias españolas han hablado de la causa eficiente y necesaria como la condición que tiene una 'consideración preeminente' en la producción de hecho dañoso". Jorge Suescún-Melo, Derecho privado. Estudios de derecho civil y comercial 
realidad, ha sido la teoría de la causalidad adecuada la que mejor recepción ha mostrado tener en las Cortes y en la doctrina. En esta medida, se hará un estudio más detenido sobre ella en el siguiente acápite, que se cierra con las críticas que se le enrostran a esta teoría.

\section{LA TESIS DE LA CAUSALIDAd ADECUADA}

La teoría de la causalidad adecuada es formulada "con la intención de limitar la responsabilidad en el campo de la causalidad, reduciendo los resultados excesivos a que conducía la teoría de la equivalencia de las condiciones" ${ }^{36}$. Como se mencionó, se trata de una concepción que goza de la mayor acogida tanto en la doctrina como en la jurisprudencia, lo que le ha permitido situarse en un sitial privilegiado a la hora de adelantar el juicio de causalidad en el derecho de daños. Por ello, resulta de suma importancia analizar qué tan eficaz es en el cumplimiento de esta finalidad, para luego plantear las críticas que se han formulado en su contra ${ }^{37}$ y presentar una teoría que se considera más propicia para cumplir el reto de desentrañar este elemento axiológico de la responsabilidad civil ${ }^{38}$.

contemporáneo, tomo I, 163, 2a ed., Legis Editores, Bogotá (2003).

36 Félix A. Trigo-Represas \& Marcelo López-Mesa, Tratado de responsabilidad civil, 434, $2^{\text {a }}$ ed., Editorial La Ley, Buenos Aires (2011).

37 Sin perjuicio de las demás críticas que se expondrán más adelante se presenta esta en referencia por ser marginal para la idea central que se intenta mostrar, "la doctrina de la adecuación causal nunca logró alejar de sí la sospecha de mezclar indiscriminadamente causalidad y culpabilidad... Sabido es que culpa y causa son, por lo menos en teoría, dos presupuestos distintos y autónomos de la responsabilidad civil. La culpa es, ante todo, factor de atribución, además de eximente, metro de cuantificación y fundamento de atracción causal. La relación de causalidad es, en cambio, un paso previo que busca imputar materialmente el daño a un sujeto. Por otra parte, a diferencia de otrora, la culpa ha sido despojada de todo componente sicológico, ético o moral, concibiéndosela en términos netamente objetivos; en cuanto a la causa, se ha receptado (casi sin paliativos) la teoría de la adecuación. Sin embargo, he aquí que cuando nos aprestamos a constatar la presencia de estos dos elementos esenciales de la responsabilidad, advertimos que los procedimientos de indagación que se utilizan al efecto, léase: la prognosis póstuma y el juicio de culpabilidad, se entremezclan al punto de volver abstrusas las pretendidas distinciones (lógico-formales) que se suelen circunscribir en derredor de la ambivalente noción de previsibilidad. En otras palabras, el juicio de culpabilidad (aprehendido en clave objetiva) se confunde con el juicio de causalidad (cuando se la escruta bajo los cánones de la adecuación) o, lo que es igual: culpa objetiva = causa adecuada. Las consecuencias de esta superfetación no son menores; así, pues, cuando la responsabilidad se imputa a título subjetivo, el examen sobre la culpabilidad del agente se vuelve una reiteración innecesaria del juicio causal". JuAn Manuel Prevot, El problema de la relación de causalidad en el derecho de la responsabilidad civil, 15 Revista Chilena de Derecho Privado, 143-178, 146 (diciembre de 2010). Disponible en: http://www.scielo.cl/scielo.php?pid=S0718$80722010000200005 \&$ script $=$ sci_arttext

38 Cfr. Javier Tamayo-Jaramillo, Tratado de responsabilidad civil, tomo I, 378, Legis Editores, 
Pues bien, para entrar en materia, vale la pena recordar que el origen de la teoría de la causalidad adecuada a Luis von Bar y a Johannes von Kries. Ciertamente, se ha señalado que se trata de una construcción que "fue elaborada en su versión original por Luis von Bar en 1871, pero su elaboración final corresponde al fisiólogo J. von Kries, (...)"39. De acuerdo con Díez-Picazo, quien sigue a Pietro Trimarchi en sus planteamientos, "Von Kries subrayó que la probabilidad, entendida como frecuencia de la relación entre dos clases de eventos, es un dato a tener en cuenta a la hora de establecer relaciones causales. Hay leyes naturales - dice Von Kries - que establecen una relación de necesaria secuencia entre dos tipos de eventos, pero otras se limitan a establecer una relación de frecuencia estadística. Von Kries ponía de manifiesto la importante función que los juicios de probabilidad tienen en la vida práctica, pues las consecuencias probables de una acción pueden servir de fundamento para valorar la acción como útil o como peligrosa. Es lógico que cuando el Derecho tiene por objeto la prevención de acciones dañosas prohíba acciones que no solo han sido condiciones sqn (sine qua non) de daños, sino que también aparecen como idóneas para producirlos en el sentido que aumentan en una medida importante la probabilidad de que se verifiquen. Además, la fuerza de la probabilidad es un juicio objetivo, que tiene en cuenta las uniformidades naturales y sociales, científicamente establecidas, en el momento en que el juicio se emite, de manera que este se realiza sobre la base de una descripción generalizador que comprenda las circunstancias del caso"40.

En el mismo orden de ideas, la Corte Suprema de Justicia de Colombia ha dicho sobre esta teoría que plantea, como postulado causal esencial, que "...de todos los antecedentes y condiciones que confluyen a la producción de un resultado, tiene la categoría de

Bogotá (2007). Félix A. Trigo-Represas \& Marcelo López-Mesa, Tratado de responsabilidad civil, 433, $2^{a}$ ed., Editorial La Ley, Buenos Aires (2011). Ramón Daniel Pizarro, Responsabilidad civil por riesgo creado y de empresa. Contractual y extracontractual, tomo I, 99, Editorial La Ley, Buenos Aires (2006). Atilio Aníbal Alterini, Responsabilidad civil, 150, $3^{\mathrm{a}}$ ed., Editorial Abeledo-Perrot, Buenos Aires (1992). Isidoro H. Goldennerg, La relación de causalidad en la responsabilidad civil, 30, Editorial Astrea, Buenos Aires (1984).

39 Gerardo Ortiz-Gómez, El nexo causal en la responsabilidad civil, en Derecho de las obligaciones, tomo II, vol. I, 324, Marcela Castro de Cifuentes, coord., Ediciones Uniandes, Editorial Temis (2010).

40 Luis Díez-Picazo y Ponce de León, Fundamentos de derecho civil patrimonial, tomo V, 364, Editorial Thomson, Civitas Ediciones, Madrid (2007). 
causa aquel que de acuerdo con la experiencia (las reglas de la vida, el sentido común, la lógica de lo razonable) sea el más 'adecuado', el más idóneo para producir el resultado, atendidas por lo demás, las específicas circunstancias que rodearon la producción del daño y sin que se puedan menospreciar de un tajo aquellas circunstancias azarosas que pudieron decidir la producción del resultado, a pesar de que normalmente no hubieran sido adecuadas para generarlo (...) como se ve, la gran elasticidad del esquema conceptual anotado, permite en el investigador una conveniente amplitud de movimiento. Pero ese criterio de adecuación se lo acompañó de un elemento subjetivo que le valió por parte de un sector de la doctrina críticas a la teoría en su concepción clásica (entonces y ahora conocida como de la 'causalidad adecuada'), cual es el de la previsibilidad, ya objetiva o subjetivamente considerada. Mas, dejando de lado esas honduras, toda vez que su entronque con la culpa como elemento subjetivo es evidente, y este es tema que no se toca en el recurso, el criterio que se expone y que la Corte acoge, da a entender que en la indagación que se haga —obviamente luego de ocurrido el daño (...) debe realizarse una prognosis que dé cuenta de los varios antecedentes que hipotéticamente son causas, de modo que con la aplicación de las reglas de la experiencia y del sentido de razonabilidad a que se aludió, se excluyan aquellos antecedentes que solo coadyuvan al resultado pero que no son idóneos per se para producirlos, y se detecte aquel o aquellos que tienen esa aptitud. Sin embargo, cuando de asuntos técnicos se trata, no es el sentido común o las reglas de la vida los criterios que exclusivamente deben orientar la labor de búsqueda de la causa jurídica adecuada, dado que no proporcionan elementos de juicio en vista del conocimiento especial que se necesita, por lo que a no dudarlo cobra especial importancia la dilucidación técnica que brinde al proceso esos elementos propios de la ciencia - no conocidos por el común de las personas y de suyo solo familiar en menor o mayor medida a aquellos que la practican - y que a fin de cuentas dan, con carácter general, las pautas que ha de tener en cuenta el juez para atribuir a un antecedente la categoría jurídica de causa. En otras palabras, un dictamen pericial, un documento técnico científico o un testimonio de la misma índole, entre otras pruebas, podrán ilustrar al juez sobre las reglas técnicas que la ciencia de que se trate 
tenga decantadas en relación con la causa probable o cierta de la producción del daño que se investiga..."41.

Así las cosas, para establecer el vínculo causal, el análisis de la causalidad adecuada sugiere que se debe determinar si un suceso era razonable y previsiblemente el más idóneo o adecuado para causar un resultado, teniendo en cuenta las máximas de la experiencia - si el asunto no requiere un especial conocimiento técnico- o las reglas de la ciencia particular — si se trata de un asunto técnico- ${ }^{42}$. Si la respuesta es positiva, esto es, si el suceso surge como idóneo para el resultado, a la luz de la experiencia y la razonabilidad, se tiene entonces que ese suceso es causa del resultado; contrario sensu, no habrá vínculo causal. A este razonamiento se le denomina prognosis póstuma ${ }^{43}$. Nótese entonces cómo se trata de un juicio fundamentado, esencialmente, en los criterios de normalidad y probabilidad, por lo que la doctrina ha puntualizado que en la causalidad adecuada es preciso hacer, en realidad, un juicio probabilístico que, por lo demás, se efectúa “...a posteriori, ex post facto y en abstracto, esto es prescindiendo de lo que efectivamente ha ocurrido en el caso concreto, y computando únicamente

41 Corte Suprema de Justicia, Sala de Casación Civil. Proceso 6878, Sentencia del 26 de septiembre de 2012. Magistrado ponente Jorge Santos-Ballesteros. Disponible en: http://www.arlsura. com/index.php?option $=$ com_content $\&$ view $=$ article $\&$ id $=223 \&$ catid $=83 \&$ Itemid $=34$

42 Sobre este juicio, Marcelo López-Meza expone: "Se denomina prognosis póstuma (pronóstico objetivo-retrospectivo) —o mejor, "juicio de adecuación causal"—al procedimiento consistente en determinar ex post facto la posibilidad de un resultado en función de las condiciones precedentes". Félix A. Trigo-Represas \& Marcelo López-Mesa, Tratado de responsabilidad civil, $2^{\mathrm{a}}$ ed., Editorial La Ley, Buenos Aires (2011). Javier Tamayo-Jaramillo, con cita de Roger O. Dalcq, así lo expresa: "Esta teoría — la de la causalidad adecuada - considera también que para ser retenido como causa de un daño, un hecho debe ser la condición necesaria de dicho daño. Entendemos por ello la condición sine qua non, es decir, aquella sin la cual el daño no se habría producido. Pero contrariamente a la afirmación de los partidarios de la equivalencia de las condiciones, la teoría de la causalidad adecuada rechaza esta equivalencia y declara que no todas las condiciones necesarias podrán ser retenidas como causas; no se retendrá más que aquellas que están unidas al daño por una relación de causalidad adecuada. Bajo esta condición suplementaria, los defensores de esta teoría entienden colocarse sobre el terreno psicológico para dar de la relación de causalidad una explicación práctica. Consideran que es necesario colocarse antes del evento para analizar el nexo de causalidad, lo que les conduce a no retener como causa sino los antecedentes de los cuales debía esperarse que produjeran el resultado que se realizó. Así, pues, esta teoría tiene por efecto eliminar entre los antecedentes, aquellos que no han ejercido un papel en la producción del daño, más que por un encadenamiento que puede ser considerado excepcional". JAVIER TAMAYO-JARAMILLO, Tratado de responsabilidad civil, tomo I, 378-379, Legis Editores, Bogotá (2007).

43 Sobre el uso de la estadística, como análisis de probabilidad, para acreditar la causalidad en materia de responsabilidad civil, se puede consultar: David W. BArnes, Too Many Probabilities: Statistical Evidence of Tort Causation, 64 Law and Contemporary Problems, 4, 191-212 (2001). Disponible en: http://papers.ssrn.com/sol3/papers.cfm?abstract_id=899804 
aquello que sucede, conforme al curso normal y ordinario de las cosas. [Max von] Rümelin hacía referencia a este fenómeno como el \pronóstico objetivo retrospectivo囚. (...) Algunos han sostenido que el juez debería colocarse en la posición del autor del hecho, tomando en cuenta las circunstancias conocidas o cognoscibles por este. La previsibilidad en tal caso no deja de ser valorada en forma abstracta, pero circunscripta al punto de vista del sujeto y a las condiciones en las que este actuó. Otros, en cambio, miran el hecho siempre objetivamente: el juez debe efectuar el juicio de previsibilidad en abstracto, tomando en cuenta todas las circunstancias que un hombre normal debería prever. Finalmente, una corriente ultraobjetiva estima necesario que el juez considere todas las circunstancias eximentes, incluso aquellas que no hubieren podido ser conocidas por el agente" $"$. El resultado puede entonces variar de acuerdo con la posición que se adopte, pues al involucrar o prescindir de uno o más hechos, la previsibilidad y la probabilidad pueden llegar a variar drásticamente. De esta forma, el juicio de causalidad dependerá en un alto grado de la capacidad del juzgador de formar un panorama lo más completo posible, quedando en todo caso una porción muy amplia a su arbitrio ${ }^{45}$. Por esta razón se ha dicho que "esta última teoría pierde rigor científico cuando percibimos las diferencias abismales que puede haber entre un juez y otro en relación con el criterio de adecuación, ya que lo que para un juez puede ser causa adecuada de un daño, para otro puede no serlo, sin que ninguno de los dos tenga argumentos científicos que justifiquen su punto de vista"46. Con todo, se ha tratado de una teoría a la que se le ha reconocido una gran utilidad práctica porque, a pesar de las subjetividades, parece brindar una explicación intuitivamente

44 Ramón Daniel Pizarro, Responsabilidad civil por riesgo creado y de empresa. Contractual y extracontractual, tomo I, 99, Editorial La Ley, Buenos Aires (2006).

45 Para Adriano de Cupis: "No cabe duda de que al acoger el criterio de la regularidad causal se atribuye amplia importancia a la apreciación discrecional del juez, del que depende establecer si el daño ha sido o no un efecto regular del hecho humano. Pero en materia de relación causal, la apreciación discrecional del juez adquiere, necesariamente, una considerable importancia; y, por último, entre los varios criterios propuestos para mitigar la dureza de la teoría de la conditio sine qua non, no hay duda de que de la regularidad ha gozado de un mayor favor en la doctrina”. Adriano de CUPIS, El daño. Teoría general de la responsabilidad civil, 259, ÁngEL Martínez-SArrión, trad., Bosch, Casa Editorial, Barcelona (1970).

46 Javier TAmayo-JARAmillo, Tratado de responsabilidad civil, tomo I, 380, Legis Editores, Bogotá (2007). 
acertada de lo que sucede en el mundo cuando afirmamos que un fenómeno es causa de otro.

Pero ¿es la causalidad adecuada una verdadera y genuina teoría sobre lo que conocemos como nexo causal? La alusión a criterios de selección normativa como la probabilidad y las máximas de la experiencia, ha develado que la causa adecuada no hace un examen de causalidad puramente físico o naturalista, sino que, por el contrario, parezca más una herramienta de selección de la causa jurídicamente relevante, a partir de un conjunto dado de causas naturales. Puesto en otros términos, la causalidad adecuada no responde cuáles son las causas físicas o naturales de un determinado evento, sino que brinda unos parámetros conforme a los cuales se puede escoger, dentro de un determinado grupo de causas, cuál es la que resulta jurídicamente más relevante.

No en vano, por ejemplo, Ramón Daniel Pizarro señala: “más allá de las objeciones, la doctrina de la relación causal adecuada tuvo el mérito de fundar sobre bases razonablemente objetivas, superadoras del empirismo reinante hasta ese momento, un criterio de delimitación de imputación. No es, en verdad, como bien se ha dicho, una genuina teoría causal, en tanto no luce orientada a determinar si un elemento de hecho es la causa de un resultado. Su finalidad es más específica: establecer si determinados hechos deben ser considerados relevantes, desde una perspectiva jurídica, para formular la imputación de sus consecuencias a una determinada persona. La teoría de la causalidad adecuada es, en esencia, una teoría de la imputación objetiva, que permite con unos criterios normativos más o menos ciertos, que un resultado pueda ser atribuido a un comportamiento" $"$. Así, la causa adecuada parece ser idónea para resolver la pregunta por cuál es la causa jurídicamente relevante y no para esclarecer cuándo un fenómeno es causante de otro, en el sentido natural de la expresión 'causa'. Esto ha sido claramente entendido en otros ordenamientos jurídicos en los que la adecuación es comprendida en su justa dimensión, esto es, como un criterio de imputación o selección causal y no como un derrotero para determinar la causalidad natural. Así se ha hecho, por ejemplo, en España, Alemania o, incluso, en los Principios de Derecho Eu-

47 Ramón Daniel Pizarro, Responsabilidad civil por riesgo creado y de empresa. Contractual y extracontractual, tomo I, 99, Editorial La Ley, Buenos Aires (2006). 
ropeo de la Responsabilidad Civil (PETL, por sus siglas en inglés), que reflejan el estado más avanzado del debate.

El inconveniente, sin embargo, es que en Colombia este aspecto no ha sido diáfanamente aprehendido. En nuestro contexto local, la teoría de la causalidad adecuada ha sido estudiada y aplicada como un criterio de causalidad fáctica o natural, y no como una forma de imputación o selección de causas. Con ello, se ha desfigurado su alcance real, lo que ha conducido a que, en ocasiones, lleve a resultados inverosímiles o contraintuitivos. Un ejemplo puede resultar muy claro para ilustrar esta problemática.

"A le da a B un golpe en la cabeza, insuficiente para provocar una lesión en un ser normal. Pero ocurre que B está afectado de una debilidad congénita de los huesos del cráneo y ese golpe le basta para matarlo. El resultado se produjo pues, pese a que el acto que ha sido la condición de ello, no debía normalmente tener semejante efecto. La teoría de la causalidad adecuada conducirá a considerar la debilidad particular de los huesos del cráneo de B como un evento excepcional, y a considerar desde luego que el acto de A no es la causa del daño porque esta consecuencia no era previsible"48. Sin embargo, la intuición más elemental llegaría a la solución justamente opuesta: el golpe, independientemente de la situación atípica o anormal, es la causa fáctica del daño producido sobre B. Cosa distinta es si esta causa resulta jurídicamente relevante a efectos de comprometer su responsabilidad, pero lo cierto es que, desde una perspectiva estrictamente causal, el impacto en el cráneo fue el que condujo al resultado. El problema es que, en cualquier caso, esa no es la respuesta a la que llega la causalidad adecuada. De manera contraintuitiva, como se señaló, este criterio causal indicaría que el golpe no fue la causa del daño. Por esta falencia, algunos teóricos se han encargado de agregarle a la causalidad adecuada elementos que permitan sopesar antecedentes que solo de manera anormal o azarosa producen el resultado. De ahí que se hayan añadido aditamentos que, con la ayuda que las ciencias forenses prestan a este propósito, permiten que, aun en esos raros casos, y junto con

48 Javier Tamayo-Jaramillo, Tratado de responsabilidad civil, tomo I, 379, Legis Editores, Bogotá (2007). 
la "lógica de lo razonable" (Luis Recaséns-Siches), estos eventos puedan esclarecerse ${ }^{49}$.

Sin embargo, estos aditamentos, de una parte, no han resuelto el problema en la práctica, comoquiera que no se puede inventar un nuevo criterio para la causalidad adecuada, con cada situación particular que surge en el mundo fáctico; pero, además, tampoco han sido capaces de resolver el problema de fondo, que es el verdadero enfoque de la adecuación como un criterio de selección de causas (imputación) y no como un derrotero para determinar la causa real o causa de hecho.

Esta circunstancia nos permite entonces afirmar que, en la actualidad, ordenamientos como el colombiano enfrentan una verdadera crisis de la causalidad. Las teorías tradicionales se han mostrado insuficientes para resolver muchos de los problemas que, en la práctica, suponen los problemas de la responsabilidad civil. De hecho, la concepción más difundida hoy, que es la causalidad adecuada, no solamente está desenfocada desde su perspectiva teórica — pues es tratada como una teoría de la causalidad fáctica cuando, en realidad, surge como un criterio de imputación-, sino que, además, conduce a resultados contraintuitivos que han llevado a que se le sumen millones de criterios casuistas que, en general, reflejan el fracaso de la teoría como una versión explicativa de la causalidad.

Esto demuestra la necesidad de incentivar entonces una reingeniería significativa del concepto de causalidad en los ordenamientos que, como el colombiano, presentan los problemas antes descritos. En la propuesta que se esboza a continuación se propone esa reingeniería, la cual parte de adoptar ciertas figuras que ya existen

49 Sobre la teoría formulada por Luis Recaséns-Siches, el profesor Javier Tamayo-Jaramillo dice: "El nexo causal se puede afirmar científicamente, pero su inexistencia o ruptura jurídica no siempre se puede decidir exclusivamente con criterio científico. En ese sentido, pensamos que la teoría del logos propuesta por Luis Recaséns-Siches y por Chaïm Perelman es de gran utilidad en la solución de este problema. De acuerdo con dicha teoría, cuando el juez debe decidir un proceso de responsabilidad civil no puede condenar a quien no haya causado el daño; pero no es lógico que desde el punto de vista de lo razonable excluya ciertos eventos que, aunque participaron físicamente en la producción del daño, jurídicamente deben considerarse extraños al hecho. El error de la doctrina tradicional consiste en olvidar que se están juzgando conductas humanas y que, por tanto, el buen sentido debe orientar al fallador al momento de decidir si la conducta del agente es o no una causa del daño". JAVIER TAMAYO-JARAMILlo, Tratado de responsabilidad civil, tomo I, 381, Legis Editores, Bogotá (2007). 
en el Derecho comparado y que podrían solucionar varios de los problemas antes descritos.

\section{CAUSALIDAD DE HEChO Y CAUSALIDAD DE DERECHO. HACIA UNA TEORÍA DE LA IMPUTACIÓN OBJETIVA50}

El primer eje de la propuesta tiene qué ver con la incorporación de una distinción estructural: la que diferencia entre causalidad de hecho y causalidad de derecho, más propiamente denominada imputación objetiva. El derecho de daños colombiano no conoce formalmente esta oposición entre causalidad de hecho y causalidad de derecho. Como se evidenció previamente, la aplicación de la teoría de la causa adecuada como esquema dogmático de causalidad fáctica o natural da lugar a múltiples equívocos, los cuales pueden zanjarse a partir de esta diferenciación. Al introducir la imputación en el estudio de la causalidad fáctica, como sucede en la teoría de la causa adecuada cuando es empleada confusamente, se presentan los resultados absurdos, desde el punto de vista causal, que se expusieron previamente y que hacen que esta construcción dogmática no emerja como la ideal para adelantar el juicio de causalidad ${ }^{51}$.

50 Como lo hace la doctrinante española Virginia Múrtula, es importante apuntar que "No está de más señalar en este punto que no debemos confundir la llamada 'responsabilidad objetiva o sin culpa' con la teoría de la 'imputación objetiva'. Así, mientras que esta última resuelve la relevancia jurídica de los elementos causales, una vez verificado el nexo causal (de acuerdo con la teoría de la equivalencia de las condiciones), a través de criterios normativos por los cuales un resultado puede ser atribuible a un comportamiento; la responsabilidad objetiva actuaría a posteriori en el juicio de responsabilidad, atribuyendo la responsabilidad al sujeto en función del riesgo creado con su actividad, que a su vez le reporta beneficios". Virginia Múrtula-Lafuente, La responsabilidad civil por los daños causados por un miembro indeterminado de un grupo, 84, Editorial Dykinson, Madrid (2005).

51 Fernando Pantaleón, citado por Santos-Ballesteros, señala: "el derecho no puede sino partir del concepto de causalidad propio de la Lógica y de las ciencias de la naturaleza: la llamada concepción nomológico-funcional de la causalidad. Los operadores jurídicos no son productores, sino consumidores de leyes causales. Por ello puede afirmarse que la decisión sobre la existencia o no de la relación de causalidad es una cuestión de hecho libre de valoraciones específicamente normativas. Por el contrario, el problema de la imputación objetiva - la función de cuyos criterios es evitar que sean puestas a cargo del responsable absolutamente todas las consecuencias de las que su conducta es causa - es una cuestión puramente jurídica, un problema de valoración a resolver con las pautas más o menos precisas, ofrecidas por el sistema normativo de responsabilidad. No es correcto, por tanto, considerar las que verdaderamente son teorías de la imputación objetiva — entre ellas la mal llamada teoría de la causalidad adecuada - como si se tratara de teorías sobre la relación de causalidad". JoRGE Santos-Ballesteros, Responsabilidad civil, tomo I, 376, $3^{\text {a }}$ ed., Editorial Temis, Pontificia Universidad Javeriana, Bogotá (2013). 
De ahí que en diferentes latitudes se haya propugnado por la distinción entre causalidad de hecho y causalidad de derecho, aunque esta no sea la denominación más acertada. Con ello se procura evitar la confusión teórica y los resultados contraintuitivos que se presentan cuando una teoría propia de la causalidad de derecho o imputación objetiva - como la teoría de la causa adecuada-, es empleada como criterio para dilucidar la causalidad fáctica, de hecho o meramente naturalista.

Esta dicotomía propone entonces distinguir entre la causalidad de hecho y la causalidad de derecho para indicar que el examen causal debe partir, en un primer estadio, de la verificación fáctica del nexo - o verificación naturalista, fundamentada en los criterios de la ciencia y de la física - (causalidad de hecho) y, una vez determinado el conjunto de causas fácticas, seleccionar aquella o aquellas que resulten jurídicamente relevantes (causalidad de derecho) ${ }^{52}$.

Puesto en otros términos, esta es una teoría que le indica al intérprete que el estudio de la causalidad no se agota en la aplicación de una sola fase, sino que, por el contrario, requiere dos etapas o estadios: uno primero, en el que se determina si fácticamente un suceso puede ser considerado como causa del otro (causalidad de hecho) y otro en el que se escogen, de las causas fácticas, aquellas que revisten importancia jurídica (causalidad de derecho) ${ }^{53}$. Este último estadio de selección es también conocido como imputación objetiva en la medida en que determina cuándo un resultado dañoso, además de ser originado fácticamente en un determinado suceso o actuación, le es también imputable objetivamente a dicha actuación, esto es, le es atribuible en términos jurídicos.

Ahora bien, para determinar los criterios conforme a los cuales debe analizarse la causalidad de hecho y la causalidad de derecho, hay múltiples posturas. Con todo, la más difundida indica que la primera de las causalidades (causalidad de hecho) debe analizarse conforme al test sine qua non (que emplea la equivalencia de las condiciones, antes explicada), mientras que la segunda (causali-

52 Cfr. Miquel Martín-Casals, La "modernización" del derecho de la responsabilidad extracontractual, en Cuestiones actuales en materia de responsabilidad civil, 11-112, Ponencia presentada a las XV Jornadas de la Asociación Española de Profesores de Derecho Civil, APDC, A Coruña, Servicio de Publicaciones de la Universidad de Murcia, Murcia (2011).

53 JAAP Spier et Al., Principios de derecho europeo de la responsabilidad civil. Comentarios a la relación de causalidad, 79 y ss., Thomson, Madrid (2012). 
dad de derecho) se mira conforme a la causalidad adecuada. Así las cosas, para los ordenamientos en los que existe esta postura, lo primero que debe hacer el operador jurídico es determinar qué sucesos pueden considerarse como causa conforme a la regla sine qua non para luego seleccionar, de ese conjunto de causas naturales, cuál es la causa jurídicamente relevante (imputación objetiva) ${ }^{54}$, de acuerdo con la causalidad adecuada.

Esta es, en esencia, la teoría de la imputación objetiva ${ }^{55}$, en la cual, en palabras de Enrique Gil-Botero, "una vez constatada o

54 EnRique GiL-Botero, La teoría de la imputación objetiva en la responsabilidad extracontractual del Estado en Colombia, en La filosofía de la responsabilidad civil. Estudios sobre los fundamentos filosófico-jurídicos de la responsabilidad civil extracontractual, 472-511, 484 y ss., CARLos Bernal-Pulido \& Jorge Fabra-Zamora, eds., Universidad Externado de Colombia, Bogotá (2013).

55 Sobre el origen de la imputación objetiva, se dice que "se encuentra en la escuela filosófica funcionalista planteada inicialmente por Jeremy Bentham (desde el utilitarismo), y luego fue retomada y desarrollada por el profesor Niklas Luhmann, quien desarrolló la teoría de los sistemas sociales y, por lo tanto, la importancia de asignación de roles a cargo de los asociados en una organización de personas. Esta visión funcionalista surge como una respuesta a la teoría del finalismo penal cuyo principal defensor fue Hans Welzel, para quien la voluntad y el querer del sujeto de derecho responsable del daño se incorporan al concepto de acción, razón por la cual el comportamiento de aquel que se encuentra conectado por una cadena sucesiva de causas y efectos hasta la producción del resultado, motivo por el cual pasó a ser conocida como la 'teoría final de la acción', cuyo sustrato principal se hallaba en las teorías causales de las ciencias naturales o empíricas, consideración adicional por la que se defendía bajo este paradigma una imputación netamente subjetiva (imputación subjetiva) fundamentada única y exclusivamente en la cognoscibilidad y exigibilidad esperada del sujeto - aspectos pertenecientes al fuero interno del actor del daño o del delito-. Esta perspectiva, como lo destaca la doctrina, consistió en el desplazamiento que generó el positivismo naturalístico en el derecho penal respecto de la causalidad propia de las ciencias exactas, en donde no caben hechos indiscutibles, sino únicamente los comprobables materialmente". EnRIQUE GIL-Botero, La teoría de la imputación objetiva en la responsabilidad extracontractual del Estado en Colombia, en La filosofía de la responsabilidad civil. Estudios sobre los fundamentos filosófico-jurídicos de la responsabilidad civil extracontractual, 472-511, 478-479, CARLos BERNAL-PULIDO \& JoRGE FABra-Zamora, eds., Universidad Externado de Colombia, Bogotá (2013). Sobre el camino que ha seguido esta teoría, Gerardo Ortiz-Gómez enseña: "Esta distinción fue hecha por primera vez para el derecho civil por el alemán Karl Larenz. La teoría, tal como la conocemos hoy, fue recogida por el penalista alemán Günther Jakobs, y se basa en el principio de confianza: suponemos que cada uno de los actores sociales hace lo que tiene que hacer, según Jakobs: 'Si en todo contacto social todos hubiesen de considerar todas las consecuencias posibles desde el punto de vista cognitivo, la sociedad quedaría paralizada. No se construiría ni se matricularía ningún automóvil, no se produciría ni se serviría alcohol, etc., y ello hasta el extremo de que a la hora de pagar sus deudas todo el mundo debería prestar atención a que el acreedor no planease realizar algo ilícito con el dinero recibido'. Así las cosas, Jakobs parte de la necesidad de que cada persona actúe de acuerdo con su función social. La teoría de la imputación objetiva fue traída al derecho civil por el profesor Fernando Pantaleón en 1990. Advierte que el tema de causa no es un problema jurídico, sino de hecho, y así las cosas, el problema de la causa es radicalmente distinto de la reflexión jurídica de poner a cargo de una persona una conducta como obra de su autor. Lo anterior significa que los abogados no podemos inventarnos la causalidad, porque eso sería tanto como desconocer lo que ocurre en el mundo real; sería inventar un universo paralelo donde todo se explicaría jurídicamente: 
verificada la existencia de un daño, es indiscutible que este tuvo una génesis material o causal, hecho que es irrelevante para el derecho, precisamente porque se mantiene en el plano de las ciencias naturales, es decir, en relación causa efecto. Por el contrario, verificada la existencia de un daño desde la dimensión jurídica, lo relevante es establecer a quién es atribuible esa afectación que sufre una determinada persona en sus derechos, bienes o intereses legítimos. Es precisamente en ese específico escenario donde el término imputación supone un análisis bifronte o dual consistente en la verificación de que el daño es tanto fáctica (imputatio facti) como jurídicamente (imputatio iure) imputable. La imputación fáctica tiene como propósito determinar si en el plano material, mas no necesariamente causal, el daño es atribuible o no a un sujeto de derecho. Así las cosas, antes de abordar el análisis de la imputación jurídica o el fundamento de la responsabilidad, es imprescindible que la lesión o afectación antijurídica esté radicada en cabeza de la entidad o del sujeto pasivo de la relación. Una vez constatado lo anterior, es posible abordar el análisis sobre la imputación jurídica, esto es si existe o no, un fundamento normativo que concrete, en el caso específico, la obligación de resarcir el daño antijurídico. En otros términos, la imputación fáctica - y con ella la imputación objetiva del daño-consiste en un estudio retrospectivo que recae sobre la acción u omisión del sujeto, mientras que la imputación jurídica supone la realización de un análisis prospectivo y netamente normativo dirigido a determinar si, una vez establecida la atribución material del daño, existe o no el deber jurídico — subjetivo u objetivo - de resarcir el perjuicio. Así mismo, resulta pertinente destacar que el hecho de que la imputación fáctica tenga un sustrato o contenido material no quiere significar que esté desprovista de conceptos o construcciones normativas o jurídicas y, por lo tanto, es allí donde la imputación objetiva y todos sus elementos delimitadores se conectan para suministrar una serie de herramientas a la hora de valorar cuándo es imputable o no un daño" ${ }_{56}$. Nótese

\footnotetext{
'los operadores jurídicos no son productores sino consumidores' de leyes causales. Dado el reciente planteamiento de la teoría del derecho civil, esta debe entenderse como una teoría en construcción (...)". Gerardo OrTiz-Gómez, El nexo causal en la responsabilidad civil, en Derecho de las obligaciones, tomo II, vol. I, 328, Marcela CASTro de Cifuentes, coord., Ediciones Uniandes, Editorial Temis (2010).

56 Enrique Gil-Botero, La teoría de la imputación objetiva en la responsabilidad
} 
entonces cómo se parte de un escenario dicotómico en el que se diferencia entre dos estadios de análisis ya explicados: el de la causa de hecho o causalidad fáctica, que responde a la cuestión de si un determinado fenómeno es, desde el punto de vista naturalista, el detonante de un resultado, para luego pasar a la fase de la causa de derecho o imputación objetiva, que sirve para seleccionar cuál es la causa jurídicamente relevante dentro del consabido grupo de causas naturalistas o de hecho ${ }^{57}$.

Ahora bien, para acometer el primero de los estadios del análisis, esto es, el de la causalidad de hecho, se decía entonces que se requiere un criterio que permita determinar, con cierta fiabilidad, cuáles son los sucesos que desde la óptica meramente fáctica o científica pueden considerarse como causas del resultado. Para ello se ha recurrido entonces al que parece ser el test más idóneo, que es el de la conditio sine qua non, empleado por la teoría de la equivalencia de las condiciones. Ciertamente, como ya se puso de presente en un segmento precedente, aunque este criterio ha sido criticado como teoría predominante de la causalidad, ha demostrado ser de gran utilidad cuando se le emplea única y exclusivamente con el

extracontractual del Estado en Colombia, en La filosofía de la responsabilidad civil estudios sobre los fundamentos filosófico-jurídicos de la responsabilidad civil extracontractual, 472511, 474-475, Carlos Bernal-Pulido \& Jorge Fabra-Zamora, eds., Universidad Externado de Colombia, Bogotá (2013).

57 Sobre esta dicotomía se ha afirmado, desde lo penal, que "la imputación objetiva, en sus inicios, surge vinculada al problema de la teoría de la relevancia típica que aparece en la dogmática neoclásica, neokantiana, caracterizada fundamentalmente por el llamado dualismo metodológico que, al contrario de lo que acontecía con el método naturalista, afirmó que uno era el método de las ciencias naturales y otro el de las ciencias sociales, pues al paso que aquellas se soportan en causalidad, en estas su suporte es la filosofía de los valores. Con esta separación, la dogmática neokantiana hizo una yuxtaposición del valor frente a la realidad, haciendo desaparecer la fusión entre el ser y el deber ser que, más adelante, reaparece con la dogmática finalista al entender la acción como una unidad de sentido en que se funde, nuevamente, el valor con el ser, tal como la entendía [Hans] Welzel. (...) Otra repercusión de la dogmática neokantiana, con su dualismo metodológico, fue la teoría de la relevancia típica que parte de la teoría causal de la equivalencia de las condiciones, en donde todas las condiciones contribuyen por igual a la producción del resultado en la medida en que si se suprime, mentalmente, una de ellas el resultado no se consigue, de conformidad con la teoría de la conditio sine qua non. Pero si bien para la teoría de la relevancia típica todas las condiciones tienen idéntico valor desde el punto de vista causal, no todas las condiciones son relevantes para el tipo penal. (...) En principio, entonces, la teoría de la imputación objetiva surge como un desarrollo de relevancia típica vinculada, inicialmente, a solucionar fundamentalmente el problema de la atribución de resultados, es decir, determinar si se puede imputar el resultado a una determinada persona, tal como en sus inicios la concibió [Claus] Roxin". Gustavo Adolfo Villanueva-Garrido, El funcionalismo y la imputación objetiva, 55-57, $2^{\mathrm{a}}$ ed., Ediciones Nueva Jurídica, Bogotá (2011). 
propósito de verificar cuáles son las causas físicas o naturales de un fenómeno. El test sine qua non, basado en el explicado juicio contrafáctico, es muy apropiado para identificar todo el conjunto de variables que hicieron posible la ocurrencia de un suceso, ya que permite determinar cuándo, al omitir una de tales variables, desaparece el resultado. En ese sentido, desde un punto de vista estrictamente físico, se erige como una teoría muy sugestiva.

Puesto en otros términos, al emplear un juicio contrafáctico, el test sine qua non permite dilucidar, definitivamente, qué factores han sido decisivos en la producción del resultado, comoquiera que evalúa en ausencia de cuáles de ellos desaparece la consecuencia analizada. Este razonamiento tan básico conduce, en últimas, a esclarecer el universo de causas determinantes en el acaecimiento del desenlace final, lo que hace de esta idea un postulado muy sugestivo en lo que a la causalidad fáctica se refiere.

El problema se presenta cuando se le emplea como un criterio jurídico, toda vez que, al evaluar todas las posibles causas como equivalentes, no permite seleccionar aquella que es jurídicamente relevante y, por el contrario, propicia un regreso al infinito. Por eso se ha dicho que el test sine qua non es muy efectivo para esclarecer el conjunto de causas físicas de un hecho, pero muy pobre para determinar la causa que interesa al Derecho. También por esto es un criterio ideal para la causalidad de hecho, aun cuando no para la imputación objetiva o causalidad de derecho, que es justamente lo que se ha hecho en otros sistemas comparados y lo que se propone en este escrito.

No en vano expresa Javier Tamayo-Jaramillo "cualquiera que sea la teoría de la causalidad que se acoja, lo cierto es que, (...), siempre es indispensable que el fenómeno que se estudia como posible causa sea conditio sine qua non del daño. Es decir, desde el punto de vista jurídico, solo se considera causa del daño aquel fenómeno sin el cual el daño no se habría producido. Ello significa que si, en el caso concreto, el juez llega a la conclusión de que el daño de todas maneras se habría producido así no hubiera concurrido la culpa del demandado este no se considera causante de ese daño"58.

58 JaVier TAmayo-Jaramillo, Tratado de responsabilidad civil, tomo I, 384, Legis Editores, Bogotá (2007). En el mismo sentido, Salvador-Coderch y Fernández-Crende apuntan: "En una primera aproximación, la causalidad, entendida como causalidad de hecho, se determina por mediación 
El empleo del test sine qua non como criterio de imputación fáctica es retomado, por lo demás, por la experiencia comparada, que reconoce las bondades de distinguir entre causa de hecho y causa de derecho y, a su turno, de emplear el mencionado test como el idóneo para dilucidar la primera de las hipótesis. Así lo han hecho, por ejemplo, los Principios de Derecho Europeo de la Responsabilidad Civil en su artículo 3:101 (Conditio sine qua non), que indica: "Una actividad o conducta (en adelante actividad) es causa del daño de la víctima si, de haber faltado la actividad, el daño no se hubiera producido"59.

Ahora bien, en lo que tiene qué ver con la segunda fase del análisis de la causalidad, esto es, con la causalidad de derecho o imputación objetiva, ha dicho el profesor Mariano Yzquierdo que

del criterio de la conditio sine qua non (but-for test): hay causalidad cuando el daño no hubiera ocurrido de no haberse realizado la conducta, por acción u omisión del demandado". PABLo Salvador-Coderch \& Antonio Fernández-Crende, Causalidad y responsabilidad, 329 InDret - Revista para el Análisis del Derecho, 3, 1-25, 3 (enero de 2006). Disponible en: http://www. indret.com/pdf/329_es.pdf, http://www.raco.cat/index.php/InDret/article/view/80976/105448

59 Sobre las tendencias europeas en la materia, el profesor Patrice Jourdain afirma: "Le droit français ne définit pas le lien de causalité. Il n'indique explicitement sa préférence pour aucune des théories proposées par la doctrine. Les projets de réforme ne le font pas davantage, les rédacteurs ayant refusé de prendre un parti qui aurait risqué d'être aussitôt démenti par les tribunaux, eu égard à leur pratique habituelle. À cet égard les projets européens tranchent nettement avec notre droit. Les PETL [Principles of European Tort Law] énoncent à l'art. 3:101: 'Est considérée comme cause du dommage subi par la victime toute activité ou conduite (ci-après 'activité') en l'absence de laquelle le dommage ne serait pas survenu' et les auteurs du DCFR [Draft Common Frame of Reference] sont dans le même sens, dans l'art. 4:101: 'Une personne cause à autrui un dommage juridiquement pertinent si ce dommage doit être considéré comme une conséquence de la conduite de cette personne ou de la source de danger dont la personne est responsable'. Néanmoins, derrière cette différence formelle, on retrouve une idée semblable. Les textes européens optent tous deux pour la doctrine dite de l'équivalence des conditions ou de la condition sine qua non, que ne renie nullement le droit français. Bien des auteurs estiment d'ailleurs qu'elle représente dans la jurisprudence française la tendance dominante, à défaut de constituer un véritable principe. Souvent en effet les juges commencent par élaborer un raisonnement contrefactuel (ou but for test) en se demandant si, sans le fait (c'est-à-dire dans un scénario contraire à celui de l'espèce), le dommage se serait quand même produit. La causalité ne sera admise qu'en cas de réponse négative, c'est-à-dire si le fait apparaît comme une cause nécessaire du dommage. De ce point de vue, le caractère plus ou moins direct du lien comme la concurrence d'autres causes du dommage, simultanées ou successives, sont normalement sans incidence. Au stade des principes, droit français et projets européens convergent largement". PATRice Jourdain, La causalité (18 de febrero de 2014). Disponible en: http://grerca.univ-rennes1.fr/digitalAssets/288/288515_pjourdain2.pdf. Grupo de derecho europeo de la responsabilidad civil, Principios de Derecho Europeo de la Responsabilidad Civil, PETL. Disponible en: http://civil.udg.edu/php/biblioteca/items/298/ PETLSpanish.pdf. Study Group on a European Civil Code \& Research Group on EC Private Law (Acquis Group), Principles, Definitions and Model Rules of European Private Law, Draft Common Frame of Reference, DCFR, Christian von Bar, Eric Clive \& Hans Schulte-Nölke, eds., Sellier, European Law Publishers, GmbH, Münich, Germany (2009). Disponible en: http://ec.europa.eu/justice/policies/civil/docs/dcfr_outline_edition_en.pdf 
"resulta desde esta perspectiva una auténtica cuestión de derecho (...). Una vez decidido que existe relación causal, resta ver si, existiendo varios protagonistas la secuencia, ha de ser uno u otro el que responda, y de cuántas consecuencias. Y para ello podrán servir el criterio de la adecuación, el de la eficiencia, el de la proximidad o el que sea. Pero esto es ya un problema de imputación objetiva, no de causalidad. Ya no se trata de una cuestión dejada a la exclusiva soberanía del Tribunal de instancia, sino de una auténtica quaestio iuris cuyo tratamiento uniforme corresponde adoptar precisamente al Tribunal Supremo"

Así, en lo que consiste la imputación objetiva o causalidad de derecho es, esencialmente, en una etapa de selección; una etapa en la que, dado un conjunto de causas físicas del resultado, se escoge cuál de todas ellas es la que resulta jurídicamente relevante y, de contera, la que puede llevar a que se comprometa la responsabilidad. Así, "su aplicación sirve para negar la equiparación absoluta entre la prueba de la relación de causalidad - stricto sensu o causalidad fáctica o material - y la atribución de responsabilidad civil. Conforme esta teoría, que goza cada día de mayor predicamento en la doctrina civil, el problema causal se reduce —o se extiende - a través de diversos criterios de imputación (como el de exclusión del "riesgo general de la vida", o el criterio de la "prohibición de regreso", etc.), que si bien no son dogmas de contornos perfectamente dibujados (sino que tienen un cierto halo de imprecisión, pudiéndose presentar, además, de una manera interrelacionada y no excluyente), son, sin embargo, instrumentos útiles para configurar la relación de causalidad"61.

60 Mariano Yzquierdo-Tolsada, Sistema de responsabilidad civil, contractual y extracontractual, 194, Editorial Dykinson, Madrid (2001). El profesor Gerardo Ortiz afirma: "la imputación objetiva en el derecho civil propone una serie de criterios que llevan a no imputar la conducta al agresor. Dicho de otra manera: los criterios expuestos a continuación son criterios de exclusión de la imputación, de modo que si se da cualquiera de ellos, se llegará a la conclusión de que el agresor causó físicamente los daños, pero que jurídicamente no le son imputables y en consecuencia no responde, dado que los daños no resultan directos". Gerardo OrTizGómEz, El nexo causal en la responsabilidad civil, en Derecho de las obligaciones, tomo II, vol. I, 329, Marcela Castro de Cifuentes, coord., Ediciones Uniandes, Editorial Temis (2010).

61 Virginia Múrtula-Lafuente, La responsabilidad civil por los daños causados por un miembro indeterminado de un grupo, 84, Editorial Dykinson, Madrid (2005). Sobre los diferentes criterios de imputación objetiva, se puede ver: Luis Díez-PiCAzo y PonCe de León, Fundamentos de derecho civil patrimonial, tomo V, 372, Editorial Thomson, Civitas Ediciones, Madrid (2007). Enrique Gil-Botero, La teoría de la imputación objetiva en la responsabilidad extracontractual del Estado en Colombia, en La filosofía de la responsabilidad civil. Estudios sobre 
Ahora bien, como indica la profesora Virginia Múrtula-Lafuente, para la selección de las causas jurídicas relevantes se puede emplear toda una serie de parámetros normativos que permiten realizar la mencionada selección de causas, en los términos antes expuestos.

Así, por ejemplo, los citados Principios de Derecho Europeo de la Responsabilidad Civil, tomando la distinción entre causalidad de hecho y causalidad de derecho, contienen en su artículo 3:201 los criterios de imputación objetiva de un daño. En esta norma se ordena, "que si una actividad es causa en el sentido de la Sección 1 de este Capítulo [Conditio sine qua non], la cuestión de si puede ser imputada a una persona y en qué medida depende de factores como los siguientes:

c. La previsibilidad del daño para una persona razonable en el momento de producirse la actividad considerando, en especial, la cercanía en el tiempo y en el espacio entre la actividad dañosa y su consecuencia, o la magnitud del daño en relación con las consecuencias normales de tal actividad.

d. La naturaleza y valor del interés protegido (artículo 2:102).

e. El fundamento de la responsabilidad (artículo 1:101).

f. El alcance de los riesgos ordinarios de la vida.

g. El fin de protección de la norma que ha sido violada ${ }^{62}$.

los fundamentos filosófico-jurídicos de la responsabilidad civil extracontractual, 472-511, $480 \mathrm{y}$ ss., Carlos Bernal-Pulido \& Jorge Fabra-Zamora, eds., Universidad Externado de Colombia, Bogotá (2013). Íñigo Navarro-Mendizábal \& Abel B. Veiga-Copo, Derecho de daños, Editorial Thomson Reuters, Civitas, Madrid (2013). Gerardo Ortiz-Gómez, El nexo causal en la responsabilidad civil, en Derecho de las obligaciones, tomo II, vol. I, 329 y ss., MARCELA Castro de Cifuentes, coord., Ediciones Uniandes, Editorial Temis (2010). Pablo SAlvadorCoderch \& Antonio Fernández-Crende, Causalidad y responsabilidad, 329 InDret - Revista para el Análisis del Derecho, 3, 1-25, 7 y ss. (enero de 2006). Disponible en: http://www.indret. com/pdf/329_es.pdf, http://www.raco.cat/index.php/InDret/article/view/80976/105448

62 En el comentario que sobre el particular se hace a este artículo se explica: "A los efectos prácticos, cada uno de los ordenamientos jurídicos europeos tenidos en cuenta acepta que el mero hecho de que se determine una conditio sine qua non entre un daño y una actividad no significa que todos y cada uno de los daños posteriores tengan que ser indemnizados por la persona responsable. Como ya se ha mencionado más arriba, esto parece cierto incluso con respecto a Bélgica y Francia. En el fondo, el resultado de las sentencias de los tribunales de ambos países no es significativamente diferente si lo comparamos con el de otros países objeto de análisis. La diferencia real entre los distintos ordenamientos jurídicos parece consistir en que algunos perciben la cuestión tratada por el Art. 3:201 como un instrumento jurídico carente de cualquier relación con ella. No obstante, (hablando en términos teóricos) con las excepciones que se acaban de mencionar, cada ordenamiento jurídico reconoce — por supuesto- - que el cielo no puede ser el límite. Así pues, a efectos prácticos las diferencias son muy limitadas. Hemos intentado evitar los debates de este tipo distinguiendo entre la conditio sine qua non (sección 1) y el alcance de la responsabilidad (sección 2), que se encuentran juntos en el Capítulo 3 (relación de causalidad). 
De estos criterios de imputación objetiva, se hace especial mención al denominado criterio de la adecuación, consagrado en el literal a) del artículo anteriormente mencionado, y en virtud del cual, tomando los postulados de la teoría de la causalidad adecuada, "solo se puede imputar el daño a aquel cuya conducta resulta muy probable como causante del daño, según la reflexión hecha por un observador que deberá tener en cuenta los conocimientos especiales con que contaba el agresor al momento de causar el hecho. Este observador debe considerar la cuestión ex ante. Si según el observador el hecho no es causa normalmente imputable a su autor, y en ese sentido diríamos que no hay nexo jurídico entre la conducta (hecho) y el daño. Este criterio difiere de la teoría de la causalidad adecuada en quien hace la reflexión: se trata de un observador experto"63.

El criterio de la adecuación permite acometer una adecuada selección de causas, a partir de parámetros que son de interés del Derecho, como la normalidad y la previsibilidad. Así, en casos como el de la fragilidad ósea, antes comentado, se puede llegar a un resultado más coherente y sostenible: el golpe que se le propine

(...) El art. 3:201 solo entra en juego si el requisito de la sección 1 se cumple. Ello significa que una causa potencial, concurrente o alternativa puede ser suficiente.

(...) Los factores mencionados en el Art. 3:201 letras a-e se han extraído de una serie de casos que, a su vez, están tomados de la jurisprudencia nacional o inspirados en ella. Esta lista no es exhaustiva. Por esta razón, hablamos de 'factores como los siguientes'.

En la mayoría de los casos operarán diversos factores: (a), (b) y (e) son probablemente los más importantes. Como regla general, la responsabilidad no puede establecerse fácilmente si el daño no era razonablemente previsible en el momento en que la actividad se llevó a cabo, mientras que se requiere una atribución cautelosa si el criterio mencionado en el apartado (e) no se cumple. No obstante, pueden aplicarse excepciones, por ejemplo, en caso de dolo. Además, en especial en los casos de daños corporales (graves), puede resultar que se requiera una atribución más generosa para cumplir las exigencias de la justicia.

Esto último puede ilustrarse mediante los bien conocidos casos llamados de la 'cáscara de huevo'. Este tipo de casos son relativamente raros y por esta precisa razón no son previsibles en la realidad. No obstante, este daño será imputable al responsable.

Los factores relevantes pueden muy bien apuntar en direcciones distintas. Por ejemplo, el daño corporal merece una protección más intensa (Art. 2:102 párrafo 2). La responsabilidad objetiva (Art. 5:101) puede constituir una razón para que se sea reacio a imponer un alcance de la responsabilidad muy amplio. En estos casos - y en otros muchos- los factores relevantes tienen que ser ponderados unos con otros". Gustavo Ordoqui-Castilla \& Miquel MartínCASAls, Principios para un derecho americano de los contratos y principios de derecho europeo de la responsabilidad civil, 98-100, CARLos Ignacio Jaramillo-Jaramillo \& Rafael EduARdo Wilches-Durán, eds. acads., Facultad de Ciencias Jurídicas, Pontificia Universidad Javeriana, Instituto de Derecho Privado Latinoamericano \& Grupo Editorial Ibáñez, Bogotá (2011).

63 Gerardo Ortiz-Gómez, El nexo causal en la responsabilidad civil, en Derecho de las obligaciones, tomo II, vol. I, 329, Marcela Castro De Cifuentes, coord., Ediciones Uniandes, Editorial Temis (2010). 
a un sujeto que padezca esta enfermedad será, en definitiva, la causa física del resultado, aun cuando, desde la óptica de la imputación objetiva, no le será objetivamente imputable al autor, dada su anormalidad e imprevisibilidad.

Nótese cómo la distinción ofrece entonces indiscutibles ventajas:

En el ámbito colombiano, la jurisdicción de lo contencioso administrativo ha sido precursora de la aplicación de esta teoría al ámbito de la responsabilidad extracontractual del Estado ${ }^{64}$. En reiterados pronunciamientos, el Consejo de Estado ha echado mano de la teoría de la imputación objetiva para señalar a las entidades estatales como responsables del daño e imponerles la obligación de reparar.

Así, al reconocer diferencia entre imputación fáctica e imputación jurídica, en diversas sentencias ha precisado: "En cuanto a la imputación exige analizar dos esferas: a) el ámbito fáctico, y; b) la imputación jurídica, en la que se debe determinar la atribución conforme a un deber jurídico (que opera conforme a los distintos títulos de imputación consolidados en el precedente de la Sala: falla o falta en la prestación del servicio — simple, presunta y probada - ; daño especial — desequilibrio de las cargas públicas, daño anormal-; riesgo excepcional). Adicionalmente, resulta relevante tener en cuenta los aspectos de la teoría de la imputación objetiva de la responsabilidad patrimonial del Estado. (...) Sin duda, en la actualidad todo régimen de responsabilidad patrimonial del Estado exige la afirmación del principio de imputabilidad, según el cual, la indemnización del daño antijurídico cabe achacarla al Estado cuando haya el sustento fáctico y la atribución jurídica. Debe quedar claro, que el derecho no puede apartarse de las 'estructuras reales si quiere tener alguna eficacia sobre las mismas. En cuanto a esto, cabe precisar que la tendencia de la responsabilidad del Estado en la actualidad está marcada por la imputación objetiva, título autónomo que 'parte de los límites de lo previsible por una persona

64 Con todo, valga aclarar, por su génesis penal, que la imputación objetiva fue utilizada primariamente para la imputación de un resultado por los tribunales de dicha especialidad. Así, se ha dicho, que "fue la Sala Penal del Tribunal Superior de Bogotá, jalonada por sentencias y salvamentos de voto del ex magistrado Abelardo Rivera-Llano, el juez que empezó, desde 1994, a utilizar los criterios de imputación objetiva para resolver asuntos relacionados con delitos culposos (...)". Gustavo Adolfo Villanueva-Garrido, El funcionalismo y la imputación objetiva, 133, 2a ed., Ediciones Nueva Jurídica, Bogotá (2011). 
prudente a la hora de adoptar las decisiones'. Siendo esto así, la imputación objetiva implica la 'atribución', lo que denota en lenguaje filosófico-jurídico una prescripción, más que una descripción. Luego, la contribución que nos ofrece la imputación objetiva, cuando hay lugar a su aplicación, es la de rechazar la simple averiguación descriptiva, instrumental y empírica de 'cuando un resultado lesivo es verdaderamente obra del autor de una determinada conducta'. (...). Dicha tendencia es la que marcó el precedente jurisprudencial constitucional, pero ampliando la consideración de la imputación (desde la perspectiva de la imputación objetiva) a la posición de garante donde la exigencia del principio de proporcionalidad es necesario para considerar si cabía la adopción de medidas razonables para prevenir la producción del daño antijurídico, y así se motivará el juicio de imputación. Dicho juicio, en este marco, obedece sin lugar a dudas a un ejercicio de la ponderación que el juez está llamado a aplicar, de tal manera que se aplique como máxima que: 'Cuanto mayor sea el grado de la no satisfacción o del detrimento de un principio, mayor debe ser la importancia de satisfacción del otro'. (...) la responsabilidad extracontractual del Estado se puede configurar una vez se demuestre el daño antijurídico y la imputación (desde el ámbito fáctico y jurídico)" ${ }^{65}$.

65 Consejo de Estado, Sala de lo Contencioso Administrativo, Sección Tercera. Proceso 20144, Fallo del 19 de agosto de 2011. Consejero ponente Jaime Orlando Santofimio-Gamboa. Disponible en: http://www.alcaldiabogota.gov.co/sisjur/normas/Norma1.jsp?i=44691. En el mismo orden de ideas se pronunció el Consejo de Estado, al afirmar: “(...) si la ciencia jurídica parte del supuesto de atribuir o endilgar las consecuencias jurídicas de un resultado (sanción), previa la constatación de que una transgresión se enmarca en una específica proposición normativa, es evidente que el nexo causal por sí mismo deviene insuficiente para solucionar el problema de la atribución de resultados, tal y como desde hace varios años se viene demostrando por el derecho penal, lo que ha conllevado a que se deseche el principio de causalidad a efectos de imputar un hecho, para dar aplicación a una serie de instrumentos e ingredientes normativos (v. gr., el incremento del riesgo permitido, la posición de garante, el principio de confianza, la prohibición de regreso, etc.) dirigidos a establecer cuándo determinado resultado es imputable a un sujeto. Lo anterior, comoquiera que es posible que un determinado suceso tenga origen material en una específica conducta (causa material), pero las consecuencias del mismo sean atribuidas a un tercero (v. gr., la responsabilidad por el hecho de las cosas, o por el hecho de otro". Consejo de Estado, Sala de lo Contencioso Administrativo, Sección Tercera. Proceso 17994, Fallo del 26 de marzo de 2009. Consejero ponente Enrique Gil-Botero. En esta misma línea, en la sentencia del 9 de junio de 2010 se dio aplicación a la imputación objetiva en los siguientes términos: "En el caso concreto, el análisis de imputación desborda el plano de lo material y fáctico para ubicarse en un escenario normativo que se traduce, en sí mismo, en un ejercicio de imputación objetiva que permite determinar si el daño es o no atribuible al municipio demandado. En otros términos, si bien se desconoce la causa que dio origen a la lamentable muerte de Jhon Alexander Marín-Moncada, lo que prima facie, desde el plano material, configuraría una ausencia de imputación respecto del Estado, lo cierto es que desde la 
Se evidencia en la jurisprudencia contencioso administrativa que, a diferencia de lo aquí propuesto, el resultado, en sede de imputación de derecho ha desarrollado un conjunto de instrumentos para la atribución del resultado, entre los que se encuentran "i) el riesgo permitido; ii) el principio de confianza; iii) la posición de garante; iv) la acción a propio riesgo v) la prohibición de regreso, y vi) el fin de protección de la norma", así el criterio de la adecuación, que en este trabajo se señala como el ideal para imputatio iuris no es abordado en materia de responsabilidad del Estado.

De esta forma, para que el Estado sea responsable no es necesario que su actuación, desde una prognosis póstuma, tenga como resultado normal o probable la causación del daño. Por lo que,

perspectiva del derecho, el estudio de la misma enseña que esta no solo puede ser fáctica, sino también normativa que para el caso, se estructura en la dimensión de la imputación objetiva y, concretamente, de la omisión. En consecuencia, el hecho de que el daño tenga su génesis directa, material y causal en una acción ajena a la administración pública no quiere significar, en principio, que se haya configurado una causa extraña que exonere de responsabilidad, toda vez que aquel puede devenir imputable a esta última si su comportamiento fue relevante y determinante en el desencadenamiento del mismo, bien porque se contribuyó con una acción en la producción (v. gr. con un aumento del riesgo permitido o un desconocimiento del principio de confianza), o si pudiendo evitarlo se abstuvo de enervar su generación, esto último, siempre y cuando se constate en estos eventos que la entidad demandada se encontraba en posición de garante, es decir, que de conformidad con el ordenamiento jurídico estuviera compelida a evitar el resultado. Por consiguiente, si bien la imputación fáctica tiene un sustrato material o causal, lo cierto es que no se agota allí, ya que dada su vinculación con ingredientes normativos es posible que en sede de su configuración se establezca que un daño en el plano material sea producto de una acción u omisión de un tercero o de la propia víctima, pero resulte imputable al demandado siempre que se constate la ocurrencia de cualquiera de los siguientes aspectos: i) con fundamento en el ordenamiento jurídico se tenía el deber de impedir la materialización del daño (posición de garante); ii) con su actividad se incrementó el riesgo permitido (creación de un riesgo jurídicamente desaprobado); o iii) se estaba dentro del ámbito de protección de una norma de cuidado". Consejo de Estado, Sala de lo Contencioso Administrativo, Sección Tercera. Proceso 19385, Fallo del 9 de junio de 2010. Consejero ponente Enrique Gil-Botero. Disponible en: http://www.consejodeestado.gov.co/sentencias\%20boletin/boletin\%2066/ tercera/66001-23-31-000-1998-00569-01(19385).doc. También en Sentencia del 5 de julio de 2012, el máximo Tribunal contencioso administrativo imputó un resultado a partir de esta teoría. En ese sentido, reflexionó: "La imputación fáctica tiene como propósito determinar si en el plano material, mas no necesariamente causal, el daño es atribuible o no a un sujeto de derecho. Así las cosas, antes de abordar el análisis de la imputación jurídica o el fundamento de la responsabilidad, es imprescindible que la lesión o afectación antijurídica esté radicada en cabeza de la entidad o del sujeto pasivo de la relación. Una vez constatado lo anterior, es posible abordar el análisis sobre la imputación jurídica, esto es, si existe o no, un fundamento normativo que concrete, en el caso específico, la obligación de resarcir el daño antijurídico. En otros términos, la imputación fáctica - y con ella la imputación objetiva del daño-consiste en un estudio retrospectivo que recae sobre la acción u omisión del sujeto, mientras que la imputación jurídica supone la realización de un análisis prospectivo y netamente normativo dirigido a determinar si, una vez establecida la atribución material del daño, existe o no el deber jurídico - subjetivo u objetivo - de resarcir el perjuicio". Consejo de Estado, Sala de lo Contencioso Administrativo, Sección Tercera. Proceso 31148, Sentencia del 5 de julio de 2012. Consejero ponente Jaime Orlando Santofimio-Gamboa. 
en últimas, a partir de los títulos de imputación utilizados por el Consejo de Estado, la responsabilidad del mismo, desde la óptica de la relación causal, entendida como atribuibilidad del daño, es mucho más amplia de lo que sería de aplicar los predicamentos que en este texto se exponen.

Con todo, si bien esta teoría, a partir de la diferenciación entre una causa fáctica y una jurídica logra superar gran parte de los inconvenientes que se presentaban en el pasado al utilizar los diferentes instrumentos teóricos que no contenían esta dualidad, aún persisten problemas relevantes. Se le reprocha a la imputación objetiva, "que no explique adecuadamente los casos de causalidad hipotética y alternativa, en este caso además hay un criterio de exclusión de imputación que puede agravar este último problema, a saber: el criterio del incremento del riesgo o de la conducta alternativa correcta" ${ }^{\prime 6}$. Estos inconvenientes serán abordados en una segunda parte de este escrito en la que, a modo de perfeccionamiento de la teoría, se expondrán los distintos argumentos que podrían llevar a una eventual solución de problemas como los descritos (sobredeterminación causal, entre otros).

66 Gerardo Ortiz-Gómez, El nexo causal en la responsabilidad civil, en Derecho de las obligaciones, tomo II, vol. I, 332, Marcela CASTRo De Cifuentes, coord., Ediciones Uniandes, Editorial Temis (2010). 


\section{CONCLUSIÓN}

Esta es pues, una evidencia académica de las distorsiones que padece actualmente el examen de causalidad. El uso indiscriminado de la teoría de la causa adecuada, por fuera de su concepción y diseño original, ha llevado a resultados contraintuitivos que dificultan enormemente el examen de causalidad y lo llevan a solo dos extremos posibles: el de la excesiva permisividad o el del excesivo rigor. De ahí la importancia de adoptar un criterio de distinción entre las causas de hecho y las causas de derecho; la dicotomía permitirá estructurar un análisis que, con suficiencia, aborde la causa fáctica pero, al mismo tiempo, limite sus excesos a partir de una imputación objetiva, lo que, aunque con algunos problemas subsistentes - que se abordarán en una segunda parte de este escrito-, soluciona gran parte de las distorsiones ya denunciadas. Así las cosas, debe seguirse adelante con el debate y, lo que es más importante, adoptar posiciones crítico-reflexivas sobre el particular, ya sea para defender el estado actual o para proponer un nuevo panorama pero, en cualquier caso, con una adecuada argumentación, que permita el debate nacional e internacional. No se puede olvidar que, como decía Adriano de Cupis, "Cuanto más sobria es la intervención del legislador en la normación de la relación causal respecto a la responsabilidad civil, tanto más ardua es la función del intérprete en la solución de las difíciles cuestiones que se presentan en esta materia"67.

67 Adriano de Cupis, El daño. Teoría general de la responsabilidad civil, 249, Ángel MartínezSARrión, trad., Bosch, Casa Editorial, Barcelona (1970). 


\section{BIBLIOGRAFíA}

\section{Libros}

Abbagnano, Nicola, Diccionario de filosofía, Fondo de Cultura Económica, FCE, México (1987).

Alterini, Atilio Aníbal, Responsabilidad civil, $3^{\mathrm{a}}$ ed., Editorial Abeledo-Perrot, Buenos Aires (1992).

Brian, Bix H., Diccionario de teoría jurídica, Instituto de Investigaciones Jurídicas, Universidad Nacional Autónoma de México, UNAM, México (2009).

CUPIS, AdriAno De, El daño. Teoría general de la responsabilidad civil, Ángel MarTínezSARrión, trad., Bosch, Casa Editorial, Barcelona (1970).

Díez-Picazo y Ponce de León, Luis, Derecho de daños, Civitas, Madrid (1999).

Díez-Picazo y Ponce de León, Luis, Fundamentos de derecho civil patrimonial, tomo V, Editorial Thomson, Civitas Ediciones, Madrid (2007).

Goldenberg, Isidoro H., La relación de causalidad en la responsabilidad civil, Editorial Astrea, Buenos Aires (1984).

Medina-Alcoz, María, La culpa de la víctima en la producción del daño extracontractual, Editorial Dykinson, Madrid (2003).

Múrtula-Lafuente, Virginia, La responsabilidad civil por los daños causados por un miembro indeterminado de un grupo, Editorial Dykinson, Madrid (2005).

Navarro-Mendizábal, Íñigo \& Veiga-Copo, Abel B., Derecho de daños, Editorial Thomson Reuters, Civitas, Madrid (2013).

Ordoqui-Castilla, Gustavo \& Martín-Casals, Miquel, Principios para un derecho americano de los contratos y principios de derecho europeo de la responsabilidad civil, Carlos Ignacio Jaramillo-Jaramillo \& Rafael Eduardo Wilches-Durán, eds. acads., Facultad de Ciencias Jurídicas, Pontificia Universidad Javeriana, Instituto de Derecho Privado Latinoamericano \& Grupo Editorial Ibáñez, Bogotá (2011).

Pérez-Vives, Álvaro, Teoría general de las obligaciones, vol. II, parte primera, 4a ed., Alberto Tamayo-Lombana, rev. y actual., Ediciones Doctrina y Ley Ltda., Bogotá (2011).

Pizarro, Ramón Daniel, Responsabilidad civil por riesgo creado y de empresa. Contractual y extracontractual, tomo I, Editorial La Ley, Buenos Aires (2006).

Polinsky, Mitchell \& Shavell, Steven, Handbook of Law and Economics, Elsevier North-Holland, Amsterdam (2007).

Santos-Ballesteros, Jorge, Responsabilidad civil, tomo I, $3^{\text {a }}$ ed., Editorial Temis, Pontificia Universidad Javeriana, Bogotá (2013).

SpIer, JAAP ET Al., Principios de derecho europeo de la responsabilidad civil. Comentarios a la relación de causalidad, Thomson, Madrid (2012).

Suescún-Melo, Jorge, Derecho privado. Estudios de derecho civil y comercial 
contemporáneo, tomo I, 2 ${ }^{\mathrm{a}}$ ed., Legis Editores, Bogotá (2003).

TAmayo-Jaramillo, Javier, Tratado de responsabilidad civil, tomo I, Legis Editores, Bogotá (2007).

Tourneau, Philippe Le, La responsabilidad civil, Legis Editores, Bogotá (2010).

Trigo-Represas, Félix A. \& López-Mesa, Marcelo, Tratado de responsabilidad civil, $2^{\mathrm{a}}$ ed., Editorial La Ley, Buenos Aires (2011).

Velásquez-Posada, Obdulio, Responsabilidad civil extracontractual, Editorial Temis, Universidad de La Sabana, Bogotá (2009).

Villanueva-Garrido, Gustavo Adolfo, El funcionalismo y la imputación objetiva, 2a ed., Ediciones Nueva Jurídica, Bogotá (2011).

Yzquierdo-Tolsada, Mariano, Sistema de responsabilidad civil, contractual y extracontractual, Editorial Dykinson, Madrid (2001).

\section{Colaboración en obras colectivas}

Cárdenas-Mejía, Juan Pablo, Causa extraña como eximente de responsabilidad, en Derecho de las obligaciones, tomo II, vol. I, Marcela Castro de Cifuentes, coord., Ediciones Uniandes, Editorial Temis (2010).

Gil-Botero, Enrique, La teoría de la imputación objetiva en la responsabilidad extracontractual del Estado en Colombia, en La filosofía de la responsabilidad civil. Estudios sobre los fundamentos filosófico-jurídicos de la responsabilidad civil extracontractual, 472-511, Carlos Bernal-Pulido \& Jorge Fabra-Zamora, eds., Universidad Externado de Colombia, Bogotá (2013).

Martín-Casals, Miquel, La "modernización" del derecho de la responsabilidad extracontractual, en Cuestiones actuales en materia de responsabilidad civil, 11-112, Ponencia presentada a las XV Jornadas de la Asociación Española de Profesores de Derecho Civil, APDC, A Coruña, Servicio de Publicaciones de la Universidad de Murcia, Murcia (2011).

Ortiz-Gómez, Gerardo, El nexo causal en la responsabilidad civil, en Derecho de las obligaciones, tomo II, vol. I, Marcela Castro de Cifuentes, coord., Ediciones Uniandes, Editorial Temis (2010).

Pizarro, Ramón Daniel, Causalidad adecuada y factores extraños, en Derecho de daños. Homenaje al profesor Jorge Mosset-Iturraspe, FÉLIX A. TRIGO-RePRESAs \& RubÉN Stiglitz, dirs., La Rocca, Buenos Aires (2000).

Quézel-Ambrunaz, Christophe, Définition de la causalité dans le droit français, en La causalité dans le droit de la responsabilité civile européenne, Troisième Séminaire du Groupe de Recherche Européen sur la Responsabilité Civile, GRERCA, 26-27 mars 2010, Université de Genève (2010). Disponible en: https://hal.archivesouvertes.fr/hal-00485806/document 


\section{Revistas}

Alexander, Larry A., Causation and Corrective Justice: Does Tort Law Make Sense?, 6 Law and Philosophy, 1, 1-23 (April, 1987).

BARAONA-GONZÁlez, JoRge, La cuestión causal en la responsabilidad civil extracontractual: panorama de derecho comparado, 31 Revista Chilena de Derecho, 2, 211-223 (diciembre de 2004). Disponible en: dialnet.unirioja.es/descarga/articulo/2650453. pdf

Barnes, David W., Too Many Probabilities: Statistical Evidence of Tort Causation, 64 Law and Contemporary Problems, 4, 191-212 (2001). Disponible en: http://papers. ssrn.com/sol3/papers.cfm?abstract_id $=899804$

Engle, Eric, Aristotelian Theory and Causation: The Globalization of Tort, 2 Gujarat National Law University Law Review, 1, 1-18 (octubre de 2009). Disponible en: http://papers.ssrn.com/sol3/papers.cfm?abstract_id=1424693

Prevot, Juan Manuel, El problema de la relación de causalidad en el derecho de la responsabilidad civil, 15 Revista Chilena de Derecho Privado, 143-178 (diciembre de 2010). Disponible en: http://www.scielo.cl/scielo.php?pid=S071880722010000200005\&script=sci_arttext

Salvador-Coderch, Pablo \& Fernández-Crende, Antonio, Causalidad y responsabilidad, 329 InDret - Revista para el Análisis del Derecho, 3, 1-25 (enero de 2006). Disponible en: http://www.indret.com/pdf/329_es.pdf, http://www. raco.cat/index.php/InDret/article/view/80976/105448

Solarte-Rodríguez, Arturo, Los actos ilícitos en el Derecho Romano, 107 Vniversitas, 691-746 (2004). Disponible en: http://www.javeriana.edu.co/juridicas/pub_rev/ documents/18solarte.pdf

\section{Mimeo}

Hinestrosa, Fernando, Curso de obligaciones (conferencias), $2^{\mathrm{a}}$ ed. mimeo, Facultad de Derecho de la Universidad Externado de Colombia, Bogotá (1961).

\section{Normatividad internacional}

Alemania, Bürgerliches Gesetzbuch, Código Civil, 24 de agosto de 1896. Disponible en: http://www.gesetze-im-internet.de/bgb/BJNR001950896.html, http://www. gesetze-im-internet.de/englisch_bgb/index.html\#gl_p3448

Alemania, UmweltHG, Ley del Medio Ambiente, 10 de diciembre de 1990. Disponible en: http://www.gesetze-im-internet.de/bundesrecht/umwelthg/gesamt.pdf

España, Real Decreto de 24 de julio de 1889 por el que se publica el Código Civil, Disponible en: https://www.boe.es/buscar/act.php?id=BOE-A-1889-4763

Francia, Ley del 21 de marzo de 1804, Código Civil. Disponible en: http://www. legifrance.gouv.fr/affichCode.do?cidTexte=LEGITEXT000006070721 
Grupo de derecho europeo de la responsabilidad civil, Principios de Derecho Europeo de la Responsabilidad Civil, PETL. Disponible en: http://civil.udg.edu/php/ biblioteca/items/298/PETLSpanish.pdf

Study Group on a European Civil Code \& Research Group on EC Private Law (Acquis Group), Principles, Definitions and Model Rules of European Private Law, Draft Common Frame of Reference, DCFR, Christian von Bar, Eric Clive \& Hans Schulte-Nölke, eds., Sellier, European Law Publishers, GmbH, Münich, Germany (2009). Disponible en: http://ec.europa.eu/justice/policies/civil/docs/ dcfr_outline_edition_en.pdf

\section{Normatividad colombiana}

Código Civil, Ley 57 de 1887. Disponible en: http://www.alcaldiabogota.gov.co/sisjur/ normas/Norma1.jsp?i=39535

\section{Jurisprudencia nacional y extranjera}

Consejo de Estado, Sala de lo Contencioso Administrativo, Sección Tercera. Proceso 17994, Fallo del 26 de marzo de 2009. Consejero ponente Enrique Gil-Botero.

Consejo de Estado, Sala de lo Contencioso Administrativo, Sección Tercera. Proceso 19385, Fallo del 9 de junio de 2010. Consejero ponente Enrique Gil-Botero. Disponible en: http://www.consejodeestado.gov.co/sentencias\%20boletin/ boletin\%2066/tercera/66001-23-31-000-1998-00569-01(19385).doc

Consejo de Estado, Sala de lo Contencioso Administrativo, Sección Tercera. Proceso 20144, Fallo del 19 de agosto de 2011. Consejero ponente Jaime Orlando Santofimio-Gamboa. Disponible en: http://www.alcaldiabogota.gov.co/sisjur/ normas/Norma1.jsp?i=44691

Consejo de Estado, Sala de lo Contencioso Administrativo, Sección Tercera. Proceso 31148, Sentencia del 5 de julio de 2012. Consejero ponente Jaime Orlando Santofimio-Gamboa.

Corte Suprema de Justicia, Sala de Casación Civil. Proceso 52835-3103-001-2000-0000501, Sentencia del 16 de mayo de 2011. Magistrado ponente William NaménVargas. Disponible en: https://redjusticiaambientalcolombia.files.wordpress. com/2014/06/csj16-mayo2011.pdf

Corte Suprema de Justicia, Sala de Casación Civil. Proceso 6878, Sentencia del 26 de septiembre de 2012. Magistrado ponente Jorge Santos-Ballesteros. Disponible en: http://www.arlsura.com/index.php?option=com_content\&view=article\&id $=223 \&$ catid $=83 \&$ Itemid $=34$

New York Court of Appeals, Palsgraf v. Long Island Railroad Co., 248 N.Y. 339, 162 N.E. 99 (N.Y. 1928), decided May 29, 1928. Disponible en: http://www.law. berkeley.edu/files/Palsgraf_NYCA.pdf 


\section{Sitios web}

Un perro cae al vacío y provoca tres muertes consecutivas, $A B C$, lunes 24 de octubre de 1988. Disponible en: http://hemeroteca.abc.es/nav/Navigate.exe/hemeroteca/ madrid/abc/1988/10/24/089.html

Jourdain, Patrice, La causalité (18 de febrero de 2014). Disponible en: http://grerca. univ-rennes1.fr/digitalAssets/288/288515_pjourdain2.pdf 
